\title{
Construction of a high-density mutant library in soybean and development of a mutant retrieval method using amplicon sequencing
}

Mai Tsuda ${ }^{1,2}$, Akito Kaga ${ }^{1 *}$, Toyoaki Anai ${ }^{3}$, Takehiko Shimizu' ${ }^{1}$ Takashi Sayama ${ }^{1}$, Kyoko Takagi ${ }^{1,4}$, Kayo Machita ${ }^{1}$, Satoshi Watanabe ${ }^{1,3}$, Minoru Nishimura ${ }^{1,5}$, Naohiro Yamada ${ }^{6}$, Satomi Mori ${ }^{1}$, Harumi Sasaki ${ }^{1}$, Hiroyuki Kanamori ${ }^{1}$, Yuichi Katayose ${ }^{1}$ and Masao Ishimoto ${ }^{1}$

\begin{abstract}
Background: Functions of most genes predicted in the soybean genome have not been clarified. A mutant library with a high mutation density would be helpful for functional studies and for identification of novel alleles useful for breeding. Development of cost-effective and high-throughput protocols using next generation sequencing (NGS) technologies is expected to simplify the retrieval of mutants with mutations in genes of interest.

Results: To increase the mutation density, seeds of the Japanese elite soybean cultivar Enrei were treated with the chemical mutagen ethyl methanesulfonate (EMS); M2 seeds produced by M1 plants were treated with EMS once again. The resultant library, which consisted of DNA and seeds from 1536 plants, revealed large morphological and physiological variations. Based on whole-genome re-sequencing analysis of 12 mutant lines, the average number of base changes was 12,796 per line. On average, 691 and 35 per line were missense and nonsense mutations, respectively. Two screening strategies for high resolution melting (HRM) analysis and indexed amplicon sequencing were designed to retrieve the mutants; the mutations were confirmed by Sanger sequencing as the final step. In comparison with HRM screening of several genes, indexed amplicon sequencing allows one to scan a longer sequence range and skip screening steps and to know the sequence information of mutation because it uses systematic DNA pooling and the index of NGS reads, which simplifies the discovery of mutants with amino acid substitutions.

Conclusions: A soybean mutant library with a high mutation density was developed. A high mutation density ( 1 mutation/74 kb) was achieved by repeating the EMS treatment. The mutation density of our library is sufficiently high to obtain a plant in which a gene is nonsense mutated. Thus, our mutant library and the indexed amplicon sequencing will be useful for functional studies of soybean genes and have a potential to yield useful mutant alleles for soybean breeding.
\end{abstract}

Keywords: EMS mutagenesis, Mutant library, High resolution melting, Next generation sequencing, Mutation density, Amplicon sequencing, Nextera technology, HiSeq, MiSeq, DNA pooling

\footnotetext{
* Correspondence: kaga@affrc.go.jp

${ }^{1}$ Agronomics Research Center, National Institute of Agrobiological Sciences,

2-1-2 Kannondai, Tsukuba, Ibaraki 305-8602, Japan

Full list of author information is available at the end of the article
} 


\section{Background}

Soybean [Glycine $\max$ (L.) Merr.] is a major source of the world's protein, oil, and animal feed [1]. The reference genome sequence ( $975 \mathrm{Mb}$ ) [2] comprises 54,175 predicted protein-coding loci. The functions of most of these predicted genes have not been clarified. A mutant library with a high mutation density would be helpful for obtaining such functional evidence. Soybean has a paleopolyploid genome and nearly $75 \%$ of predicted soybean genes are present in multiple copies due to two duplication events at 13 and 59 mya [3]. Compared with diploids, polyploid species can better withstand higher mutation densities because of compensation by other genome copies [4, 5], as additional gene copies may mask the phenotypic effect of a mutation. However, RNA-seq analysis of transcriptional divergence of duplicated genes by neo-functionalization has shown that approximately $50 \%$ of duplicated genes were differentially expressed in soybean [6]. Retention of the ancestral function by one of the duplicated genes and acquisition of a novel function by the other [7, 8] may result in phenotypic changes despite the high genetic redundancy in the soybean genome.

Gamma ray is the most commonly used physical mutagens in plant mutation breeding [9] and induces deletions [10]. One of the reverse genetics approaches, induction of point mutations by chemical mutagenesis, known as TILLING (targeting-induced local lesions in genomes) [11], has been widely used to discover the biological functions of sequenced genes and to develop novel alleles associated with specific traits in several crop species such as maize [12], wheat [4], rice [13], sorghum [14], soybean [15], tomato [16], and canola [17]. Ethyl methanesulfonate (EMS), N-nitroso-N-methylurea (NMU), and ethyl nitrosourea (ENU) constitute $64 \%$ of all agents used for chemical mutagenesis (reviewed in [18]). In soybean, EMS is commonly used, and diverse mutant phenotypes have been reported (reviewed in [19]). Mutation densities of up to $1 / 140 \mathrm{~kb}$ detected by TILLING have been reported in EMS- or NMU-induced mutant population [15]. According to Anai [20], the mutation rate, $1 / 769 \mathrm{~kb}$, which was detected from mutant population by repeated EMS treatment of soybean increased from the mutation rate, $1 / 2500 \mathrm{~kb}$, which was detected from another mutant population by a single treatment of EMS.

A heteroduplex mismatch cleavage assay based on mismatch-specific endonuclease Cel I is the most established method to detect point mutations [11, 21], but in this method the reaction conditions depend on the target region [22]. High resolution melting (HRM) analysis $[23,24]$ has been recently applied as an alternative simple, rapid, and inexpensive method for mutant discovery in tomato [25] and wheat [26], although its accuracy depends on the quality of PCR, resolution of the instruments, and the choice of fluorescent dyes [24]. Some types of base changes (such as $\mathrm{C}$ to $\mathrm{G}$ or A to $\mathrm{T})$ are more difficult to detect by HRM than other types due to the small differences in melting temperatures [27]. Sanger sequencing [28] is generally required as the final step of mutation screening to confirm the base changes and whether the mutation causes an amino acid substitution.

Next generation sequencing (NGS) technologies provide accurate and rapid detection of mutations. NGS platforms such as Roche 454 pyrosequencing [29], sequencing-by-synthesis [30], SOLiD sequencing [31], and Ion Torrent sequencing [32] were released from 2005 to 2010. The HiSeq 2000 (Illumina, San Diego, CA, USA) became the standard of high-throughput sequencing; it uses sequencing-by-synthesis chemistry. With the widespread use of HiSeq 2000, Illumina launched an alternative platform MiSeq, compact bench-top sequencers. Sequencing with MiSeq, which is also based on sequencing-by-synthesis chemistry, has lower throughput (up to $15 \mathrm{~Gb}$ yield per run of $300 \mathrm{bp}$ reads) than HiSeq 2000 (up to $600 \mathrm{~Gb}$ yield per run of $100 \mathrm{bp}$ ), but it is cheaper, faster, and easier to use [33]. However, accurate detection of single nucleotide variants (SNV) requires sequencing coverage of $20 \times$ to $30 \times$ for a diploid genome [34], and re-sequencing of large populations is still expensive. An alternative, cheaper method is sequencing of PCR amplicons in targeted regions, so-called amplicon sequencing $[17,35,36]$. A combination of a pooling strategy and sequencing in the targeted region by NGS platforms has been examined [34, 37]. The drawbacks and limitations of sequencing pooled samples by NGS include difficulties in distinguishing low-frequency alleles from sequencing errors, the need to adjust the DNA concentration, occurrence of misalignment to the reference sequence due to high error rates, and short sequence reads [37]. Nextera (Illumina), a library construction method referred to as tagmentation, combines DNA fragmentation and DNA tagging in a single reaction of transposase-mediated adaptor insertion [38]. This method enables convenient and quick genomic library construction for highthroughput sequencing [38, 39]. Development of such cost-effective and high-throughput commercial products based on NGS technologies may simplify the retrieval of mutants with mutations in the target genes.

In the present study, we constructed a high-density mutant library of soybean, which provide a potential to yield new alleles for soybean breeding. An efficient method of mutant discovery in the library, which uses DNA pooling and a new commercial dual indexing system for the amplicon sequencing by NGS, is described. 


\section{Results and discussion Mutant library}

Using seeds of a Japanese elite soybean cultivar Enrei, we developed a mutant library with a high mutation density to identify useful novel alleles for breeding (Fig. 1). M1 seeds were treated with $0.35 \%$ EMS; M2 seeds were collected from four per M1 plant and bulked from approximately $2000 \mathrm{M} 1$ plants, treated in a similar way to the first treatment in order to increase mutation density, and used to grow M1' plants. The generation after second EMS treatment was called M1' to discriminate it from the initial M1 generation. Populations were kept small and of the similar size in every generation. Since contamination of DNA from out-crossing plants critically impacts on estimation of mutation density and identification of mutant, out-crossing plants was carefully examined by simple sequence repeat (SSR) analysis. After all, 26 potential out-crossing plants were removed in order to preserve genetic integrity. The resultant library consisted of DNA derived from 1536 M2' plants; 1437 of which produced M3' seeds. Seeds from each line and their corresponding DNA samples were stored as a mutant library.

\section{Phenotypic variations}

Phenotypic variations were observed in the following traits: albino, the density of leaf pubescence, flowering time, flower color, internode length, the number of nodules, maturity time, pod size, seed size, and seed color. Some particular phenotypes distinct from wild-type cultivar Enrei are shown in Fig. 2 and listed in Table 1. The frequency of typical mutations, such as albino phenotype, was considerably higher in our library than in previously reported soybean mutant populations [40, 41]. The frequency of the albino phenotype mutations ( $4.9 \%)$ in a population mutagenized by using a combination of $45 \mathrm{kR}$ gamma rays and $0.2 \%$ EMS [42] was similar to $4.4 \%$ in the present library, suggesting that mutations can be accumulated by repeated mutagenesis. The frequency of the dwarf phenotype in the present library, $1.6 \%$, was higher than $0.26 \%$ reported by Karthika and Lakshmi [40] for M2 plants mutagenized with $0.2 \%$ EMS. The frequency of root nodule mutants, $0.6 \%$, was also greater than $0.04 \%$ reported in the same cultivar by Akao and Kouchi [41] despite their use of a higher EMS concentration ( $0.5 \%$ compared with $0.35 \%$ in our study). The frequency of dwarf and semi-dwarf mutants in the present library, $9.1 \%$, was considerably higher than $1.34 \%$ in a wheat population mutagenized with $0.8 \%$ EMS [4] and $2.89 \%$ in common bean $(0.6 \%$ EMS) [43]. Similarly, the frequency of albino mutants, $4.4 \%$, was higher than $0.27 \%$ in wheat [4], $1.7 \%$ in tomato [44], and $1.53 \%$ in common bean [43]. The frequencies of other crop mutants with higher concentration
(0.6-1.0 \% EMS) were even less than half the frequency compared to $0.35 \%$ EMS in our library. Thus, various mutant phenotypes to be potential target for forward genetics approach were frequently observed in the present library in comparison with other high-mutation-density mutant libraries.

Protein, oil, and sugar content in seeds harvested from M2' plants is shown in Fig. 3. In comparison with wildtype plants (protein: $46.3 \pm 0.2 \%$, oil: $19.7 \pm 0.0 \%$, sugar: $19.8 \pm 0.2 \%)$, distribution and average seed protein $(47.3 \pm 1.3 \%)$ and sugar content $(20.9 \pm 1.1 \%)$ in the library was significantly shifted toward higher values, whereas that of oil content $(18.1 \pm 1.2 \%)$ was shifted toward lower values $(p<0.01)$. The ranges of protein content (43.7-53.2 \%) and oil content (14.6-20.8 \%) became considerably wider than those of the protein content (40.8-46.4\%; $[45,46])$ and oil content (17.3-19.4\%; [46]) reported in some Japanese soybean cultivars and less than those of the protein and oil content (26.2-56.0 \%; 11.5$31.4 \%$, respectively) reported to 4400 germplasm collection [47]. A negative correlation was observed between protein and oil content $(r=-0.60, p<0.01)$, protein and sugar content $(r=-0.42, p<0.01)$, and oil and sugar content $(r=-0.39, p<0.01)$. A strong negative correlation between seed protein and oil content is commonly recognized [48-50]. Generally, phenotype reproducibility of several M2' plants with the high protein content, high sugar content and the low oil content was confirmed in their M3' progenies (Fig. 3). In contrast, phenotype reproducibility as for M2' plants with low protein, low sugar and high oil content was unclear in M3' progenies. In soybean seeds, 7S and 11S globulins comprise approximately $70 \%$ of total storage proteins [51-53]; two QTLs that determine the ratio of $7 \mathrm{~S}$ globulin to $11 \mathrm{~S}$ globulin have been identified [54]. Although many genomic regions are related to the content of seed protein [48], oil, and sugar [55], actual genes that control the content of these components have not been identified yet. Mutant lines with the maximal changes in seed protein, oil, and sugar content observed in the present study may be suitable materials for a smart forward genetics approach such as MutMap [56] that allows rapid causal gene identification for the mutant by whole-genome resequencing of pooled DNAs from segregating progenies with phenotypic differences.

\section{Mutation density}

To estimate the number of base changes per line, 12 arbitrarily selected mutant lines were re-sequenced. The cleaned short read sequences were mapped to the Williams 82 reference genome assembly. The aligned read depth ranged between 14.3 and 25 fold; genome coverage ranged between 93.6 and $94.3 \%$ (Table 2). Common base changes shared by different mutants were treated 


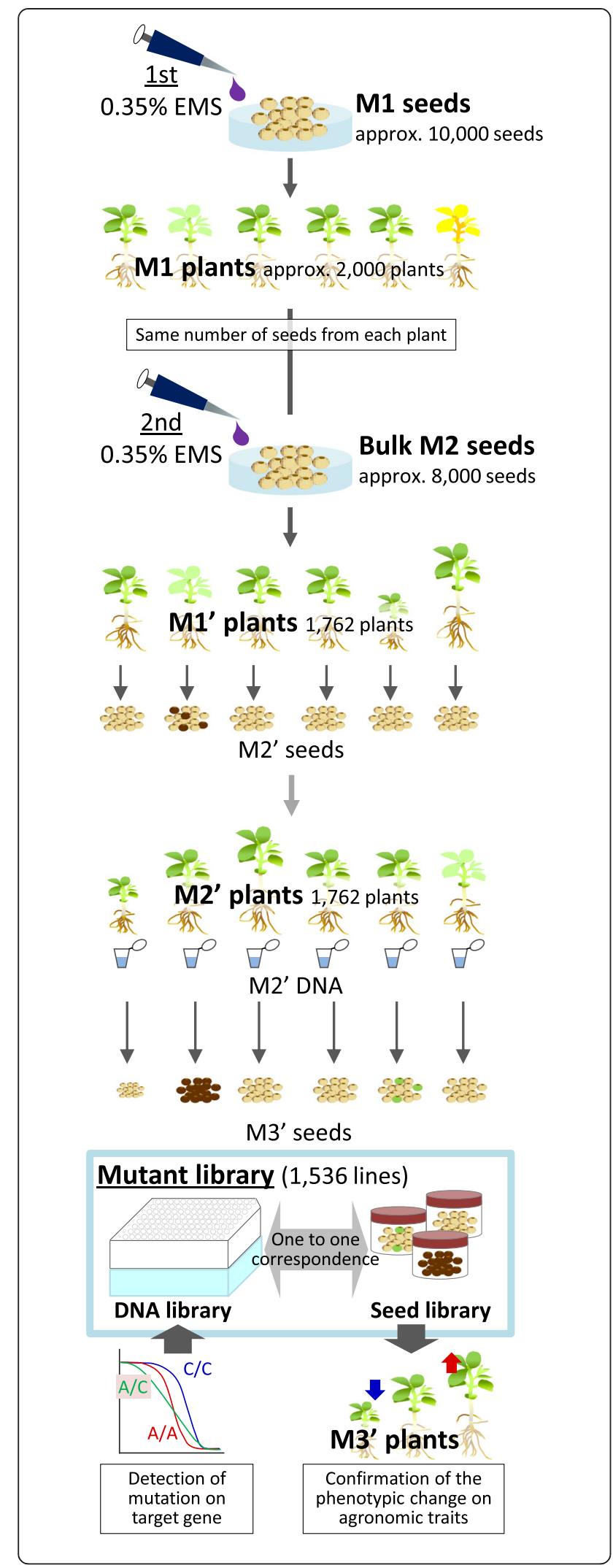

Fig. 1 Outline of the construction of the EMS-induced mutant library. Seeds were treated with a chemical mutagen (0.35\% EMS). To increase the mutation density, bulk M2 seeds from approximately 2000 M1 plants were treated again with $0.35 \%$ EMS and $8000 \mathrm{M} 2$ seeds used to grow M1' plants; the generation after the second mutagen treatment was called $\mathrm{M1}^{\prime}$ to discriminate it from the initial $\mathrm{M} 1$ generation. $\mathrm{M} 2^{\prime}$ seeds were collected each from $1762 \mathrm{M1}$ ' plants. A total of 1762 M2' plants were grown and used to extract DNA. Twenty-six potential outcrossing plants were removed, resulting in a total of $1736 \mathrm{M2}^{\prime}$ plants. The resultant library consisted of DNA derived from 1536 M2' plants; 1437 of which produced seeds. Seeds from each line were stored with their corresponding DNAs

as polymorphic sites between Enrei and Williams 82 and were filtered out. The resultant number of base changes in each mutant line ranged from 8970 to 21,861 with an average of 12,796 mutations per line (Table 2). More than $90 \%$ of base changes induced by EMS and NMU are known to be $\mathrm{G}$ to $\mathrm{A}$ and $\mathrm{C}$ to $\mathrm{T}$ transitions [18]. As expected, those transitions were most frequently observed in the mutant lines (Table 2), but the rates were lower and ranged from 53 to $77 \%$. The frequency of $\mathrm{T}$ to $\mathrm{A}$ and $\mathrm{A}$ to $\mathrm{T}$ transversions, the second most frequently observed group of mutations, ranged from 12 to $33 \%$. Among 153,554 base changes in all lines (Table 2), 106,480 G>A and $\mathrm{C}>\mathrm{T}$ transitions was predominant (69.3\%) followed by 27,306 $\mathrm{T}>\mathrm{A}$ and $\mathrm{A}>\mathrm{T}$ transversions (17.8\%), $7626 \mathrm{~T}>\mathrm{C}$ and $\mathrm{A}>\mathrm{G}$ transition (5.0\%), $5981 \mathrm{G}>\mathrm{T}$ and $\mathrm{C}>\mathrm{A}$ transversions (3.9\%), $4578 \mathrm{~A}>\mathrm{C}$ and $\mathrm{T}>\mathrm{G}$ transversions $(3.0 \%)$ and $1583 \mathrm{C}>\mathrm{G}$ and $\mathrm{G}>\mathrm{C}$ transversions $(1.0 \%)$. The transition to transversion ratio was 2.89 $(114,106 / 39,448)$. Interestingly, the rates for $G>A$ and $\mathrm{C}>\mathrm{T}$ transitions, $\mathrm{T}>\mathrm{A}$ and $\mathrm{A}>\mathrm{T}$ transversions and the transition to transversion ratio were quite similar with that reported in Tomato $(69.3 \%, 12.9 \%$ and 2.9, respectively; [57]).

On average, 727 base changes per line had the potential to cause amino acid substitutions based on the Glyma_189 annotation (Table 2). Among the base changes, 691 and 35 were missense and nonsense mutations, respectively. The distribution of mutations affecting the amino acid sequence on 20 chromosomes of two mutant lines, EnT-1634 and EnT-0964, is shown in Fig. 4. The mutation density was estimated to be approximately 1 mutation per 74 kb (range, 43-106 kb), which was much higher than expected. So far, the highest density, up to $1 / 140 \mathrm{~kb}$ induced by either $0.5 \%$ EMS or $2.5 \mathrm{mM}$ NMU, was reported in soybean [15]. The mutation density of a mutant library in this study was approximately 2 times higher than that of population. Indeed duplicated mutations should be considered to be included in the present library due to EMS treatment twice. Nonsense mutation is known to cause gain-of-function allele as well as loss-of-function allele depend on the mutation position in human disease study (reviewed in [58]). Therefore, the 

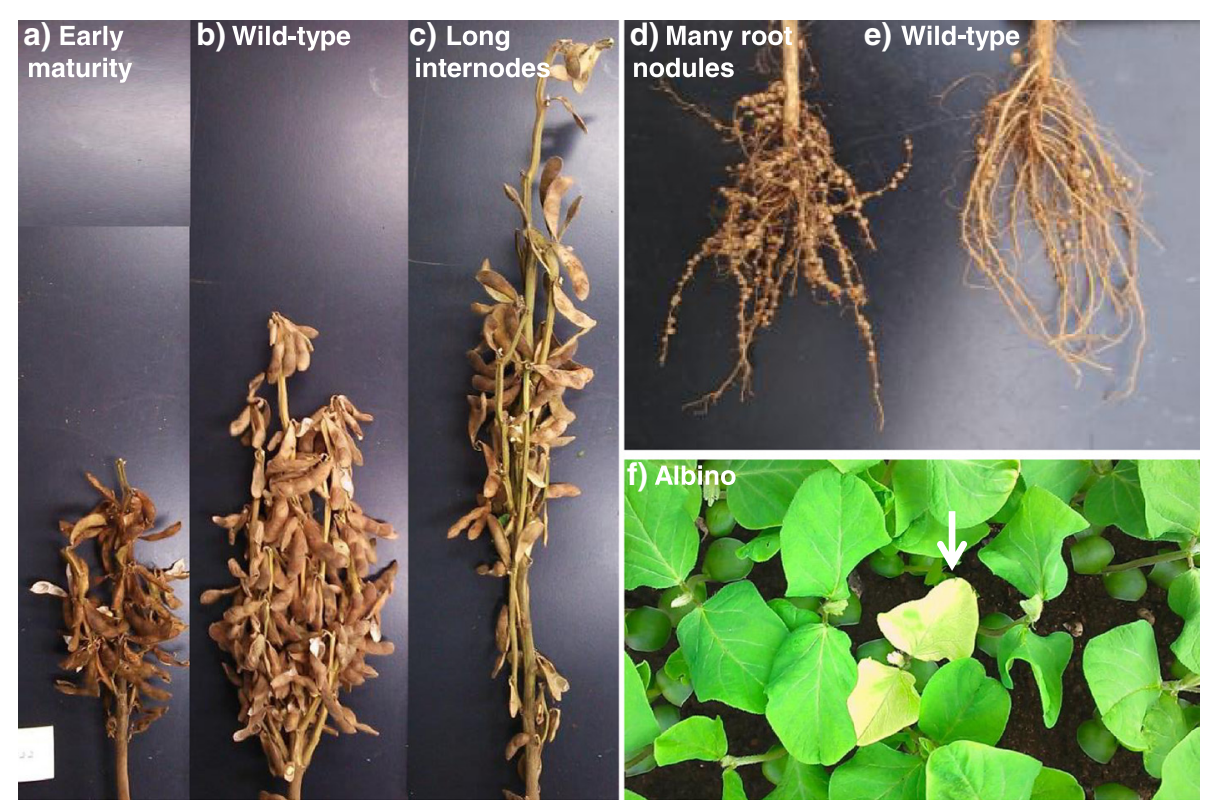

Fig. 2 Mutant phenotypes observed in the M2' plants. Wild-type: (b), (e); Mutant phenotypes: (a) Early maturity, (c) Long internodes, (d) Many root nodules, (f) Albino

present library rich in nonsense mutation has a potential to contain novel mutant allele and provide alternative useful phenotype exceed known trait variations. Although too many mutations per plant may mask the intended mutant phenotype and hamper phenotype characterization, the present library with a small population size is practical for handling, screening, and maintenance; it will provide a tool for functional studies and yield novel mutant alleles for soybean breeding.

\section{Mutant retrieval methods}

Two strategies tested here for the identification of mutants with amino acid substitutions in the mutant library are shown in Fig. 5. Advances in NGS methodologies provide cost-effective commercial products for rapid identification of sequence variations across the genome. However, the traditional method based on Sanger sequencing is still widely used to confirm the accuracy of sequences obtained by NGS. Therefore, both strategies include mutation confirmation by direct sequencing as the final step (Fig. 5). Primers for HRM analysis need to amplify short fragments of up to $\sim 300$ bp within a target gene. According to instruction manual for HRM analysis (Applied Biosystems, Foster City, CA, USA), at least three repetitions are recommended to determine DNA pool containing a mutation in PCR product. In the present study, the four original DNA samples from the DNA pool with a different HRM signature are subjected to a second round of HRM analysis or direct sequencing. If the identified mutation causes no amino acid substitution, it is necessary to return to the primer design step to amplify an alternative region.
Using our second strategy, indexed amplicon sequencing, we analyzed seven target genes (1.3-7.5 kb; $30.3 \mathrm{~kb}$ in total) amplified by long-range PCR in each DNA pool (Fig. 5). Amplicons of four samples were further pooled; this arrangement is critical to simplify re-sampling for confirmation of the mutation by direct sequencing at the final step. Dual indexing of the 96 pooled samples and sequencing library preparation were conducted with a transposome-based Nextera XT Index Kit (Illumina). Advantages of the kit are the simple procedure for fragmentation and tagmentation. The NGS read data classified by using the indexes were mapped separately onto the reference sequences of target genes. Base changes observed in more than $2 \%$ of the aligned reads were treated as a mutation; the mutations were filtered by using Glyma_189 gene annotation to exclude mutations not leading to amino acid substitutions. Since each DNA pool with a candidate mutation can be identified by sequences of the dual indexes, it was possible to detect candidate mutations without a screening step such as HRM analysis. For plants with mutations that cause amino acid substitutions, the sequences were simultaneously confirmed by direct sequencing.

\section{HRM}

The results of HRM analysis of four coding DNA sequence of Glyma20g25000 (locus Ln) (Additional file 1: Figure S1), which encodes a transcription factor responsible for leaflet shape [59], are shown as a model case in Table 3. Twenty-six plants with base changes were identified in the mutant library. Since the EMS treatment 
Table 1 Frequency of typical mutant phenotypes detected in the library

\begin{tabular}{|c|c|c|}
\hline Phenotype description & Number of plants & Frequency $(\%)^{* *}$ \\
\hline Albino (medium - heavy)* & 76 & 4.4 \\
\hline Rugose leaves, dwarf* & 11 & 0.6 \\
\hline Rugose leaves, semi-dwarf* & 20 & 1.2 \\
\hline Rugose leaves, normal & 31 & 1.8 \\
\hline Dwarf & 17 & 1.0 \\
\hline Semi-dwarf & 110 & 6.3 \\
\hline Early flowering & 46 & 2.6 \\
\hline Early maturity & 29 & 1.7 \\
\hline White flowers & 6 & 0.3 \\
\hline Violet flowers & 8 & 0.5 \\
\hline Short internodes & 2 & 0.1 \\
\hline Long internodes & 3 & 0.2 \\
\hline Narrow leaves & 8 & 0.5 \\
\hline Low-density pubescence & 3 & 0.2 \\
\hline Big primary leaves & 6 & 0.3 \\
\hline Early defoliation & 1 & 0.1 \\
\hline Easy lodging & 1 & 0.1 \\
\hline Many leaves & 1 & 0.1 \\
\hline Long peduncles & 1 & 0.1 \\
\hline Many rootlets & 2 & 0.1 \\
\hline Many root nodules & 10 & 0.6 \\
\hline No root nodules & 1 & 0.1 \\
\hline Many pods and early pod maturity & 1 & 0.1 \\
\hline Wide pods and early maturity & 2 & 0.1 \\
\hline Large seeds & 27 & 1.6 \\
\hline Deep yellow seed coat & 4 & 0.2 \\
\hline Light brown seed coat & 2 & 0.1 \\
\hline
\end{tabular}

*Most plants produced no or few seeds

**Frequency (\%) was calculated from number of mutant for each phenotype divided by $1736 \mathrm{M2}$ ' plants

was performed twice, duplicated mutations (in a homozygous or heterozygous state, Table 3) derived from M1 plants are present in the library. After removal of such duplicated mutations, the mutation density in the library was estimated as at least 15.7 mutations per $1 \mathrm{~kb}$ from the number of unique 18 mutations in the 1144-bp region. The 18 independent mutations were observed within the 1144-bp region in total, most of which were either $\mathrm{G}$ to $\mathrm{A}$ or $\mathrm{C}$ to $\mathrm{T}$ transitions except for a $\mathrm{A}$ to $\mathrm{T}$ mutation in a line EnT-1312. Among all 18 mutations, ten were missense mutations, but no nonsense mutations were detected.

Although HRM analysis detected 26 candidate lines for Glyma20g25000 in total (Table 3), Sanger sequencing showed that the mutations in 11 lines led to synonymous amino acid substitutions, which have no effect on protein structure. While excess amount of sequence confirmation by Sanger sequencing will be required to confine the candidates to meaningful mutations, simple and cost-effective HRM analysis still provides an easyto-use platform for mutation screening.

\section{Indexed amplicon sequencing}

Seven genes of a total length of $30.3 \mathrm{~kb}$ were analyzed by indexed amplicon sequencing (Table 4, Additional file 1: Figure S2). The total length of amplicons was adjusted based on the sequence output of MiSeq v2 Chemistry so that the read coverage for each sample would fall in a range between $50 \times$ and 100x. In addition to Glyma20g25000 described above, Glyma08g46520, encoding a cytochrome P450 that participates in soyasaponin biosynthesis [60]; Glyma06g23026 (maturity locus E1), encoding a transcription factor [61]; Glyma11g15580, a pseudo-response regulator family gene involved in photoperiod response [62]; and Glyma20g22160 (maturity locus E4), encoding a photoreceptor [7], Glyma05g01770 and Glyma06g19820, which encode betaine-aldehyde dehydrogenases related to soybean fragrance [63], were included in the analysis. The total read length and paired-end read counts were $6,010,609,329 \mathrm{bp}$ and 12,021,219 before trimming and 4,054,408,786 bp and 11,190,596 after trimming, respectively. After de-multiplexing the bulk of the NGS read data into 96 pools by using the indexes, read mapping on the reference gene sequences was conducted separately pool-by-pool. The total mapped read length and count for the 96 pools were 4,015,703,044 bp (99.1\%) and 22,130,334 (Table 4), respectively. The read counts for each gene varied from $1,044,416$ to $6,977,332$ depending on the length of the gene. However, relatively large variation was observed for read coverage depending on the DNA pool and sample (Table 4) as well as sample well location (Additional file 1: Figure S3). For instance, the total read number for the shortest gene Glyma06g23026 was higher than expected, and total read counts per DNA pool (average: 6097 reads) and per sample (average: 381 reads) were the highest among the examined genes. In contrast, read coverage for Glyma11g15580 was the lowest for the number of reads per DNA pool (average: 518 reads) and per sample (average: 32 reads). Since one DNA pool contained 16 samples, at least a read with a base change among 32 reads was required to detect one sample with a point mutation in a heterozygous state. Sufficient read coverage is required to distinguish between sequencing errors and low-frequency mutant alleles because of the relatively high error rates of NGS reads [37]. The average read coverage per pool and per sample obtained in this study (Table 4) might be sufficient for this purpose. However, the read coverage per pool was distributed non-uniformly across amplicons (Fig. 6). Read coverage varied by position and generally was lower in AT-rich regions and at both 

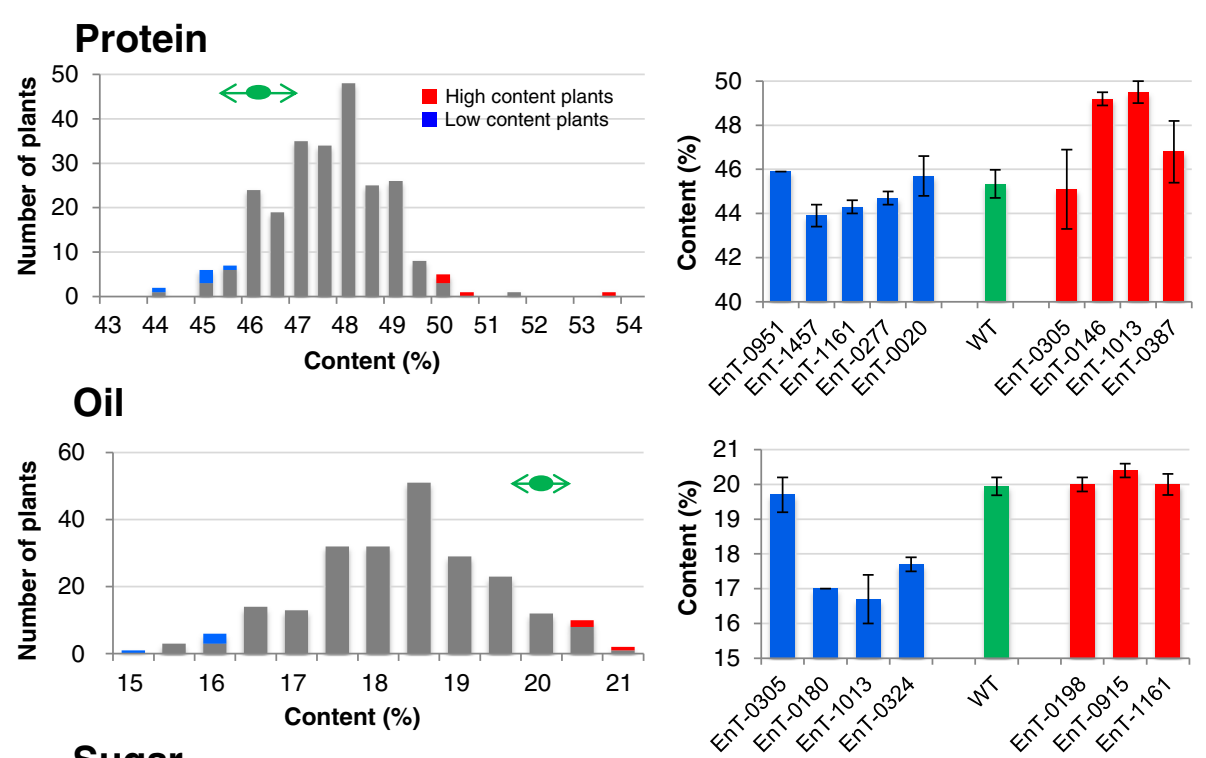

Sugar
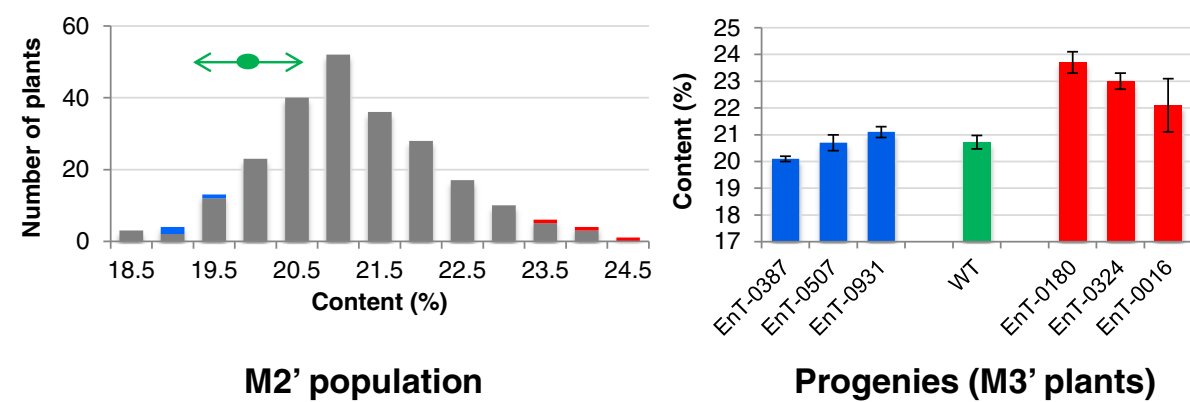

Fig. 3 Variations in protein, oil, and sugar content among seeds harvested from M2' plants and its progenies. Left histograms and right bar graphs indicate variations in protein, oil, and sugar content of the seeds harvested from M2' plants and the progenies (M3' plants), respectively. High content plants (red) and low content plants (blue) in M2' population were re-evaluated at M3' plants. In the left histograms, mean and variation for wild-type plants (WT) are indicated by green ellipses and double-headed arrows, respectively

ends of the amplicons. The percentage of base changes increased in such low-coverage regions because of an increased contribution of sequencing errors in the limited number of reads. Although the threshold for calling a mutation was set to $2 \%$ of base changes, not all base changes above $2 \%$ were called as mutations. Many base changes were excluded because the read coverage was lower than the required minimum read coverage (at least 96 reads required), or because of their absence in either forward or reverse read. The base changes that met these criteria were treated as mutations (Fig. 6, red circles).

A total of 561 unique base changes were identified in the seven genes by indexed amplicon sequencing (Table 4). Base changes at the same site were counted as one base change. In the results for several mutants, $\mathrm{G}$ to $\mathrm{A}$ and $\mathrm{C}$ to $\mathrm{T}$ transitions $(84.3 \%)$ and $\mathrm{T}$ to $\mathrm{A}$ and $\mathrm{A}$ to $\mathrm{T}$ transversions (6.2\%) were most frequently observed. Most mutations occurred in one sample (322 mutations, $57 \%$ ) but some were observed in two samples (64 mutations, $11 \%)$, there samples (18 mutations, $3 \%$ ) and four or more samples (11 mutations, $2 \%)$. The large variation in the number of base changes (from 32 to 132) was due to the variation in the length of target gene regions from 1304 to $7539 \mathrm{bp}$. The number of base changes per M2' plant were estimated by the base change frequency in each gene, and ranged from 7224 to 18,828 (average: 14,269). Similarly, the distance between base changes differed by the genes and ranged from 50 to $132 \mathrm{~kb}$ (average: $67.0 \mathrm{~kb}$ ). The mutation density and the number of mutations per plant obtained by indexed amplicon sequencing were very similar to the results of wholegenome re-sequencing (range: 43-106 kb, average: $74 \mathrm{~kb}$, Table 2). Among 561 base changes, 224 were missense mutations and nine were nonsense mutations (Table 4). Since $60 \%$ of the base changes caused synonymous amino acid substitutions, which have no effect on protein structure, indexed amplicon sequencing can effectively confine the candidates to meaningful mutations. All nonsense mutations were confirmed by Sanger sequencing (data not shown); most of them may be 
Table 2 Mutations in 12 lines detected by using whole-genome re-sequencing analysis

\begin{tabular}{|c|c|c|c|c|c|c|c|c|c|c|c|c|c|c|c|c|c|c|c|}
\hline \multirow[t]{2}{*}{ Line name } & \multirow{2}{*}{$\begin{array}{l}\text { Depth of } \\
\text { coverage }\end{array}$} & \multirow{2}{*}{$\begin{array}{l}\text { Genome } \\
\text { coverage (\%) }\end{array}$} & \multirow{2}{*}{$\begin{array}{l}\text { Number } \\
\text { of base } \\
\text { changes }\end{array}$} & \multicolumn{12}{|c|}{ Type of base change } & \multirow{2}{*}{$\begin{array}{l}\text { Amino acid } \\
\text { substitutions }\end{array}$} & \multirow{2}{*}{$\begin{array}{l}\text { Misssense } \\
\text { mutations }\end{array}$} & \multirow{2}{*}{$\begin{array}{l}\text { Nonsense } \\
\text { mutations }\end{array}$} & \multirow{2}{*}{$\begin{array}{l}\text { Distance } \\
\text { between base } \\
\text { changes }(\mathrm{kb})^{* *}\end{array}$} \\
\hline & & & & $G>A$ & $C>T$ & $\mathrm{~T}>\mathrm{A}$ & $A>T$ & $\mathrm{~T}>\mathrm{C}$ & $A>G$ & $G>T$ & $C>A$ & $A>C$ & $T>G$ & $C>G$ & $G>C$ & & & & \\
\hline EnT-0263 & 16.8 & 94.2 & 9934 & 3776 & 3481 & 635 & 718 & 266 & 300 & 202 & 206 & 135 & 117 & 60 & 38 & 573 & 543 & 30 & 95.7 \\
\hline EnT-0394 & 14.3 & 94.0 & 15579 & 5494 & 6493 & 1023 & 985 & 298 & 266 & 262 & 245 & 170 & 194 & 85 & 64 & 950 & 899 & 51 & 61.0 \\
\hline EnT-0442 & 17.0 & 94.1 & 8970 & 3612 & 3179 & 541 & 541 & 231 & 229 & 146 & 159 & 129 & 107 & 56 & 40 & 564 & 535 & 29 & 106.0 \\
\hline EnT-0541 & 23.1 & 93.9 & 15627 & 5666 & 5638 & 1120 & 966 & 459 & 452 & 338 & 334 & 237 & 220 & 103 & 94 & 823 & 785 & 38 & 60.8 \\
\hline EnT-0790 & 16.9 & 93.9 & 9366 & 3391 & 3366 & 661 & 609 & 262 & 252 & 171 & 212 & 155 & 160 & 65 & 62 & 514 & 485 & 29 & 101.5 \\
\hline EnT-0964 & 19.3 & 94.3 & 21861 & 8099 & 7688 & 1980 & 1972 & 397 & 373 & 374 & 324 & 265 & 263 & 61 & 65 & 1303 & 1246 & 57 & 43.5 \\
\hline EnT-1045 & 21.5 & 93.9 & 9172 & 2428 & 2926 & 1217 & 996 & 349 & 272 & 205 & 235 & 195 & 212 & 84 & 53 & 442 & 426 & 16 & 103.6 \\
\hline EnT-1079 & 18.0 & 94.0 & 14074 & 5376 & 5167 & 1057 & 919 & 292 & 297 & 271 & 247 & 183 & 150 & 69 & 46 & 902 & 865 & 37 & 67.5 \\
\hline EnT-1197 & 15.2 & 94.0 & 13782 & 4516 & 4877 & 1383 & 1234 & 353 & 295 & 269 & 289 & 194 & 227 & 79 & 66 & 796 & 756 & 40 & 69.0 \\
\hline EnT-1610 & 25.0 & 93.8 & 9481 & 2536 & 2874 & 1220 & 1048 & 388 & 338 & 250 & 226 & 220 & 227 & 91 & 63 & 439 & 425 & 14 & 100.3 \\
\hline EnT-1619 & 19.4 & 93.8 & 13274 & 5187 & 4122 & 1077 & 1269 & 273 & 291 & 318 & 250 & 191 & 170 & 66 & 60 & 729 & 686 & 43 & 71.6 \\
\hline EnT-1634 & 20.5 & 93.6 & 12434 & 3306 & 3282 & 1997 & 2138 & 331 & 362 & 228 & 220 & 233 & 224 & 63 & 50 & 684 & 646 & 38 & 76.5 \\
\hline Average & 18.9 & 94.0 & 12796 & 4449 & 4424 & 1159 & 1116 & 325 & 311 & 253 & 246 & 192 & 189 & 74 & 58 & 727 & 691 & 35 & 74.3 \\
\hline $\begin{array}{l}\text { Percentage of } \\
\text { each type of } \\
\text { base change }\end{array}$ & & & & $34.8 \%$ & $34.6 \%$ & $9.1 \%$ & $8.7 \%$ & $2.5 \%$ & $2.4 \%$ & $2.0 \%$ & $1.9 \%$ & $1.5 \%$ & $1.5 \%$ & $0.6 \%$ & $0.5 \%$ & & & & \\
\hline
\end{tabular}

**The distance between base changes was calculated from a total number of base changes per plant and the size of chromosome-scale assembly of the soybean genome (950,068,807 bp) 
A)

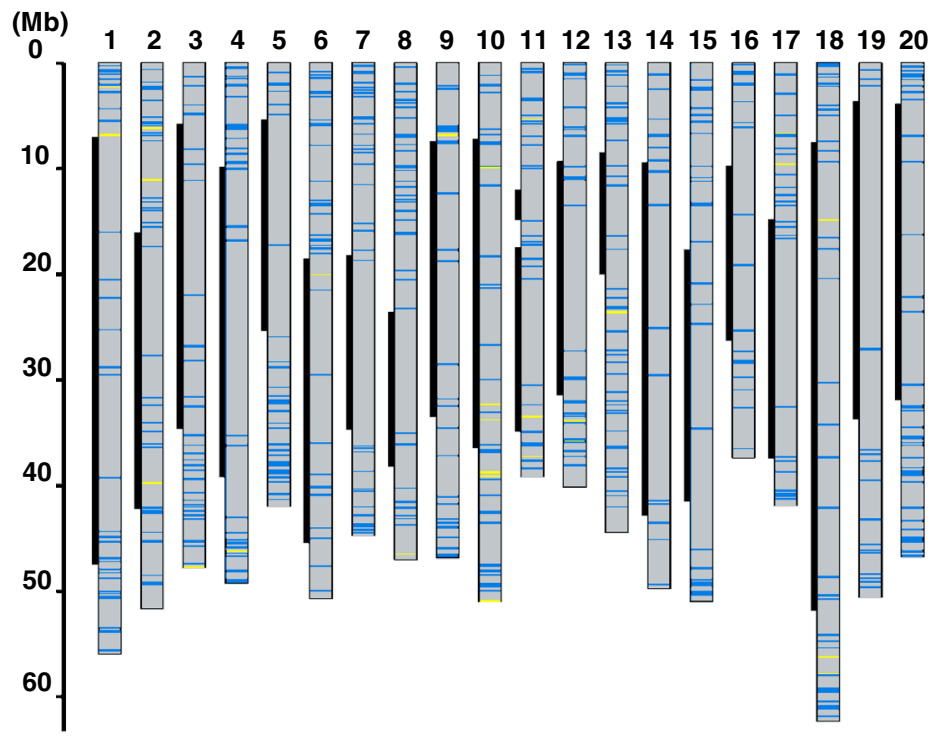

B)

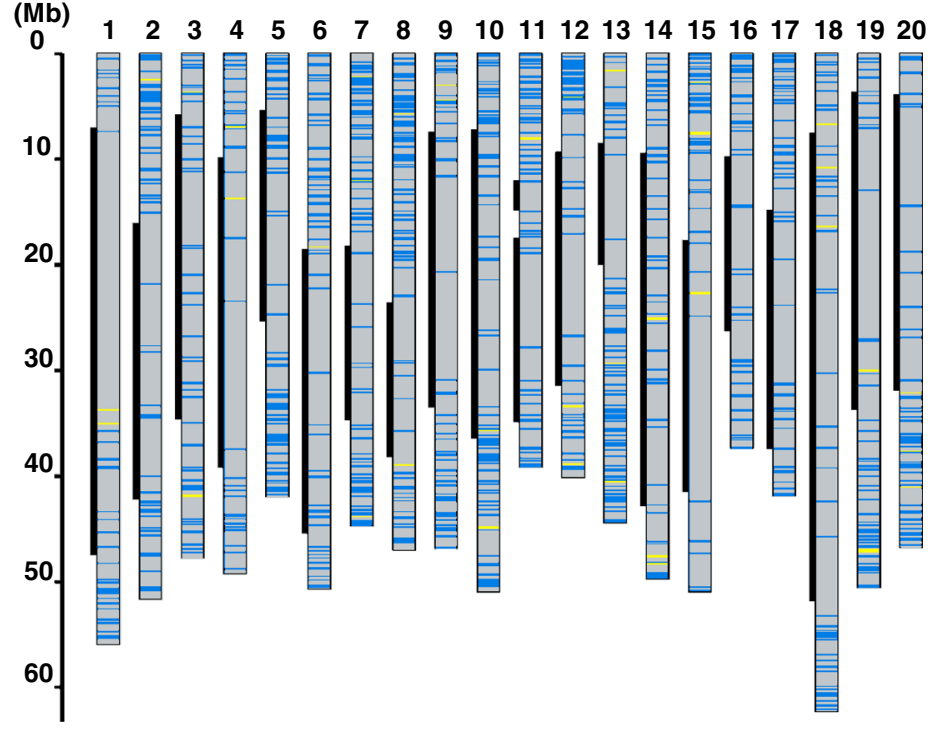

Fig. 4 Distribution of mutations affecting the amino acid sequence on 20 chromosomes of two mutant soybean lines. Blue and yellow lines on the chromosomes of two mutant lines, EnT-1634 (a) and EnT-0964 (b), indicate missense and nonsense mutations, respectively. The black line on the left of each chromosome indicates the pericentromeric region with lower gene densities than surrounding euchromatic region

useful for functional studies. Confirming the potential impact of missense mutations with the aid of the database of catalytic domain structures will be needed.

In the present study two strategies, HRM analysis and indexed amplicon sequencing, were used to screen the mutant library. Although the overall mutation density in the library and individual plants was determined by whole-genome re-sequencing analysis based on $12 \mathrm{mu}$ tants, all of mutation for the targeted genes used for indexed amplicon sequencing remained unknown in 1536 M2' mutants. To validate whether sequence variations identified by these methods provide reliable information about mutations in the whole library, the results of screening of five genes (total length of $3.5 \mathrm{~kb}$ ) were compared with the results of HRM analysis (Table 5). In addition to the results for Glyma20g25000 (Table 3), several regions of the four genes were analyzed by HRM. All 107 base changes obtained from two methods were confirmed by Sanger sequencing as the final step. HRM analysis detected $62.5 \%$ of the 107 base changes, whereas indexed amplicon sequencing identified $90.3 \%$. Most sequence variations observed in the NGS reads by indexed amplicon sequencing reflect mutations well in the library in comparison with the HRM analysis data. The failure of indexed amplicon sequencing to detect the remaining $10 \%$ of mutations was mainly due to low 


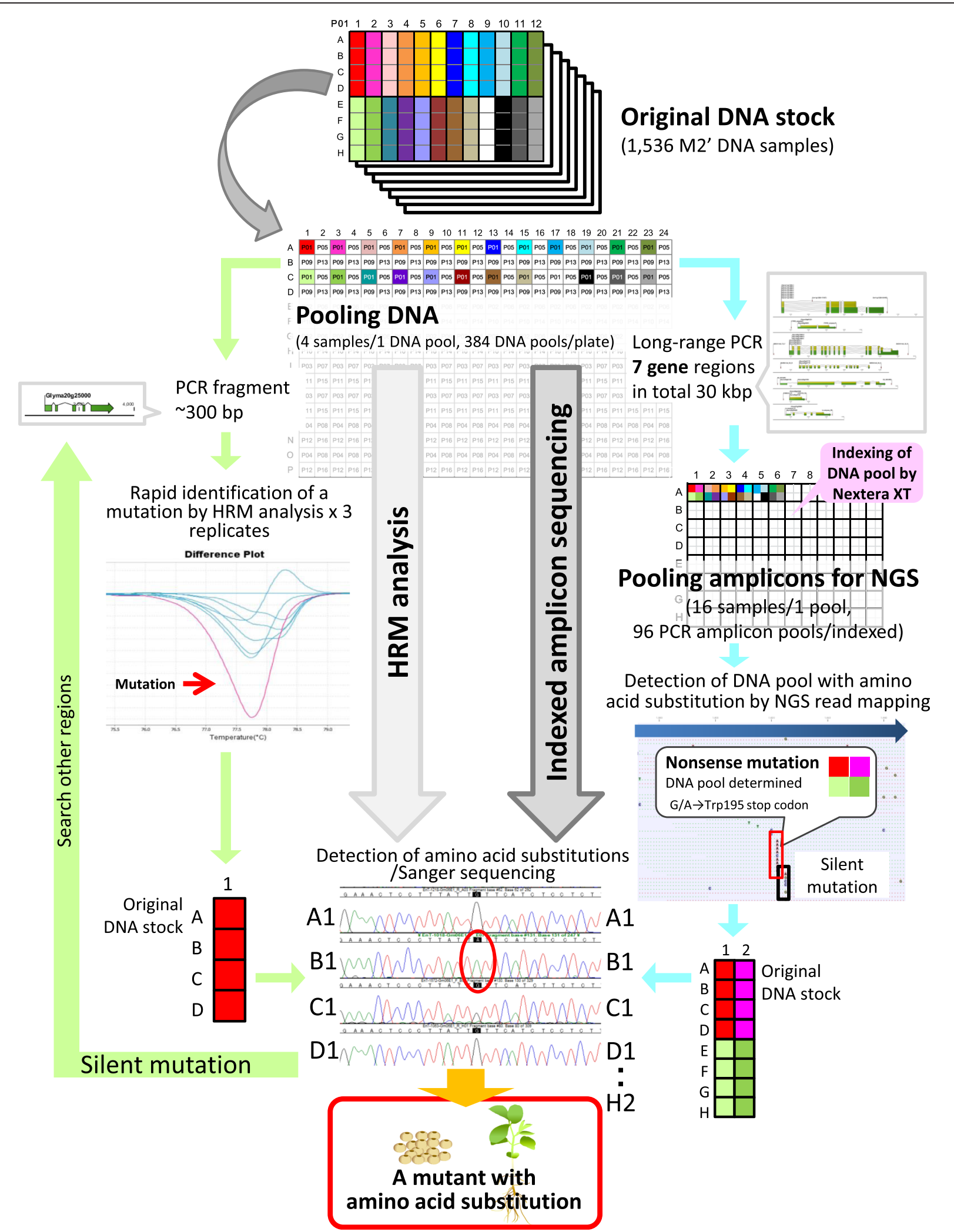

Fig. 5 (See legend on next page.) 
(See figure on previous page.)

Fig. 5 Mutant discovery by using HRM and indexed amplicon sequencing. DNA extracted from M2' plants was preserved as the original DNA stock in 96-well plates. The DNA pool in a 384-well plate (four samples per pool) was used for both methods. After a mutation was detected by HRM analysis, base changes in four original DNA samples were confirmed by direct sequencing. If the mutation was found to be silent, HRM analysis and direct sequencing of other regions were performed. In indexed amplicon sequencing, 7 target gene regions (1.3-7.5 kb, 30.3 kb in total) were amplified by long-range PCR. The amplicons of four samples were further pooled. The 96 samples were indexed by using a transposomebased Nextera XT Index kit. Bulk read data for all 96 DNA pools were obtained from Miseq and mapped onto the reference sequences of target genes after classification of the DNA pool by using indices. Base changes at high frequency in many reads were treated as a mutation and were filtered by using a Glyma_189 gene annotation to exclude mutations that did not lead to amino acid substitutions. Based on the information from DNA pool classification with indices, the base change and the plant in which it occurred could be determined by direct sequencing of each of the 16 original M2' DNA samples. Amplicon sequencing using NGS allows rapid and effective detection of DNA pools containing mutations that cause desirable functional amino acid substitutions

read depth and a uniform threshold for calling a mutation. These parameters may affect the discovery of mutations. Therefore, adjustment threshold for calling a mutation and increasing the read depth in samples is required for each gene and can improve consistency. The reasons for the lower discovery rate by HRM analysis seem to be that pooling four DNA samples is not suitable for any target regions and/or that $\mathrm{A}$ to $\mathrm{T}$ transversions are difficult to detect by HRM analysis due to their small differences in $\mathrm{T}_{\mathrm{m}}$ [27].

Table 3 Mutations in Glyma20g25000 detected by high resolution melting analysis

\begin{tabular}{|c|c|c|c|c|c|c|c|}
\hline Line name & Target region & Amplicon size $(b p)^{*}$ & Base change & Mode of mutation & Chromosome & Position (bp) & Amino acid substitution \\
\hline EnT-0541 & Ln ex1 & 332 & $G>A$ & hetero & Gm20 & 34688627 & Met1\|e \\
\hline EnT-0685 & Ln ex1 & 332 & $C>T$ & hetero & Gm20 & 34688652 & Leu10Phe \\
\hline EnT-1168 & Ln ex1 & 332 & $G>A$ & homo $^{* *}$ & Gm20 & 34688672 & Syn \\
\hline EnT-0112 & Ln ex1 & 332 & $G>A$ & homo $^{* *}$ & Gm20 & $34688682^{a}$ & Asp20Asn \\
\hline EnT-0044 & Ln ex1 & 332 & $G>A$ & hetero & Gm20 & $34688682^{\mathrm{a}}$ & Asp20Asn \\
\hline EnT-1589 & Ln ex1 & 332 & $G>A$ & hetero & Gm20 & $34688682^{\mathrm{a}}$ & Asp20Asn \\
\hline EnT-1376 & Ln ex1 & 332 & $G>A$ & hetero & Gm20 & $34688686^{b}$ & Gly21Asp \\
\hline EnT-0621 & Ln ex1 & 332 & $G>A$ & hetero & Gm20 & $34688686^{b}$ & Gly21Asp \\
\hline EnT-1048 & Ln ex1 & 332 & $C>T$ & homo $^{* *}$ & Gm20 & $34688696^{c}$ & Syn \\
\hline EnT-1306 & Ln ex1 & 332 & $C>T$ & homo** & Gm20 & $34688696^{c}$ & Syn \\
\hline EnT-0987 & Ln ex1 & 332 & $C>T$ & homo** & Gm20 & 34688713 & Ser30Phe \\
\hline EnT-0160 & Ln ex1 & 332 & $C>T$ & hetero & Gm20 & 34688719 & Ser32Phe \\
\hline EnT-0634 & Ln ex2 & 231 & $G>A$ & homo $^{* *}$ & Gm20 & $34689275^{d}$ & Gly40Ser \\
\hline EnT-0749 & Ln ex2 & 231 & $G>A$ & homo $^{* *}$ & Gm20 & $34689275^{d}$ & Gly40Ser \\
\hline EnT-0439 & Ln ex2 & 231 & $C>T$ & hetero & Gm20 & 34689313 & Syn \\
\hline EnT-1084 & Ln ex2 & 231 & $G>A$ & hetero & Gm20 & 34689360 & Gly68Glu \\
\hline EnT-1281 & Ln ex3 & 114 & $C>T$ & hetero & Gm20 & 34689704 & Ala102Val \\
\hline EnT-1312 & Ln ex3 & 114 & $A>T$ & hetero & Gm20 & 34689710 & His104Leu \\
\hline EnT-0601 & Ln ex4 & 467 & $G>A$ & homo ${ }^{* *}$ & Gm20 & 34690049 & Syn \\
\hline EnT-0155 & Ln ex4 & 467 & $G>A$ & hetero & Gm20 & 34690058 & Syn \\
\hline EnT-0687 & Ln ex4 & 467 & $C>T$ & homo ${ }^{* *}$ & Gm20 & $34690175^{\mathrm{e}}$ & Syn \\
\hline EnT-0862 & Ln ex4 & 467 & $C>T$ & homo** & Gm20 & $34690175^{e}$ & Syn \\
\hline EnT-1619 & Ln ex4 & 467 & $G>A$ & hetero & Gm20 & 34690246 & Gly213Asp \\
\hline EnT-1265 & Ln ex4 & 467 & $C>T$ & homo** & Gm20 & $34690247^{f}$ & Syn \\
\hline EnT-0510 & Ln ex4 & 467 & $C>T$ & hetero ${ }^{* * *}$ & Gm20 & $34690247^{f}$ & Syn \\
\hline EnT-0383 & Ln ex4 & 467 & $C>T$ & hetero & Gm20 & $34690247^{f}$ & Syn \\
\hline
\end{tabular}

*The amplicon size does not include primer sequences

**Base changes in a homozygous state probably occurred in M1 plants

***Base changes in a heterozygous state are probably derived from the same M1 plants as those labeled with ** Syn indicates synonymous site at which a base substitution does not cause an amino acid substitution Superscripts a to $f$ indicate that the mutation was duplicated in plants labeled with the same letter 
Table 4 Read coverage and mutations in seven genes identified by using indexed amplicon sequencing

\begin{tabular}{|c|c|c|c|c|c|c|c|c|c|c|c|c|c|c|c|c|c|}
\hline \multirow[t]{2}{*}{ Gene locus* } & \multirow{2}{*}{$\begin{array}{l}\text { Amplicon } \\
\text { size (bp) }\end{array}$} & \multirow{2}{*}{$\begin{array}{l}\text { Consensus } \\
\text { length (bp) }\end{array}$} & \multirow{2}{*}{$\begin{array}{l}\text { Total read } \\
\text { counts for } \\
96 \text { DNA } \\
\text { pools }\end{array}$} & \multicolumn{3}{|c|}{ Read coverage per sample } & \multirow{2}{*}{$\begin{array}{l}\text { Base } \\
\text { changes }\end{array}$} & \multicolumn{5}{|c|}{ Type of base change } & \multirow{2}{*}{$\begin{array}{l}\text { Amino acid } \\
\text { substitutions }\end{array}$} & \multirow{2}{*}{$\begin{array}{l}\text { Misssense } \\
\text { mutations }\end{array}$} & \multirow{2}{*}{$\begin{array}{l}\text { Nonsense } \\
\text { mutations }\end{array}$} & \multirow{2}{*}{$\begin{array}{l}\text { Total } \\
\text { number } \\
\text { of base } \\
\text { changes } \\
\text { expected } \\
\text { per M2' } \\
\text { plant** }\end{array}$} & \multirow{2}{*}{$\begin{array}{l}\text { Distance } \\
\text { between } \\
\text { base } \\
\text { changes } \\
(\mathrm{kb})^{* * *}\end{array}$} \\
\hline & & & & Average & Minimum & Maximum & & $\bar{G}>A$ & $C>T$ & $T>A$ & $A>T$ & Others & & & & & \\
\hline Glyma06g19820 & 7539 & 7519 & 3476540 & 54 & 13 & 137 & 88 & 46 & 30 & 1 & 4 & 7 & 30 & 29 & 1 & 7224 & 132 \\
\hline Glyma05g01770 & 5643 & 5625 & 3844251 & 80 & 5 & 172 & 67 & 26 & 35 & 1 & 2 & 3 & 26 & 25 & 1 & 7348 & 129 \\
\hline Glyma08g46520 & 2531 & 2514 & 1476507 & 69 & 18 & 166 & 77 & 31 & 36 & 2 & 6 & 2 & 44 & 43 & 1 & 18828 & 50 \\
\hline Glyma06g23026 & 1304 & 1294 & 4156094 & 381 & 33 & 1188 & 32 & 17 & 12 & 1 & 0 & 2 & 12 & 10 & 2 & 15188 & 63 \\
\hline Glyma20g22160 & 6390 & 6370 & 6977332 & 130 & 35 & 276 & 132 & 61 & 56 & 1 & 3 & 11 & 72 & 69 & 3 & 12785 & 74 \\
\hline Glyma11g15580 & 4214 & 4190 & 1155194 & 32 & 8 & 124 & 101 & 36 & 35 & 0 & 3 & 27 & 28 & 27 & 1 & 14833 & 64 \\
\hline Glyma20g25000 & 2648 & 2623 & 1044416 & 47 & 10 & 137 & 64 & 26 & 26 & 2 & 9 & 1 & 21 & 21 & 0 & 14958 & 64 \\
\hline Total & 30269 & 30135 & 22130334 & & & & 561 & & & & & & 233 & 224 & 9 & (av.) 14269 & (av.) 67.0 \\
\hline
\end{tabular}

Percentage of

each type of

$43.3 \% \quad 41.0 \% \quad 1.4 \% \quad 4.8 \% \quad 9.4 \%$

*Gene locus names are indicated according to gene models in the Glyma_189 assembly (v1.1)

**The total number of base changes per M2' plant was calculated from a total number of base changes in the library estimated from the amplicon size and the size of chromosome-scale assembly of the soybean genome $(950,068,807 \mathrm{bp})$ and then divided by the total number of plants (1536)

${ }_{* * *}$ The distance between base changes was calculated from the size of the amplicon divided by the total number of base changes found in the library

****The percentage of each type of base change was calculated from a total each type of base change in seven genes divided by all base changes 


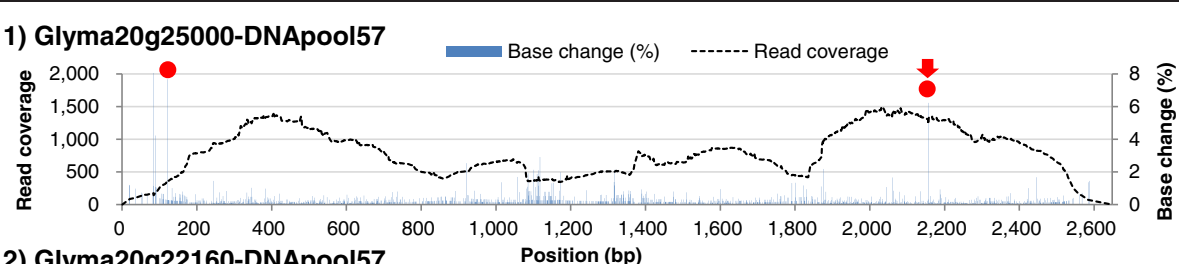

2) Glyma20g22160-DNApool57

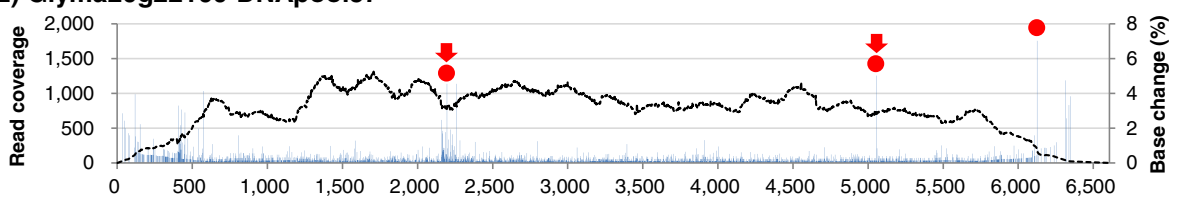

3) Glyma08g46520-DNApool57 Position (bp)

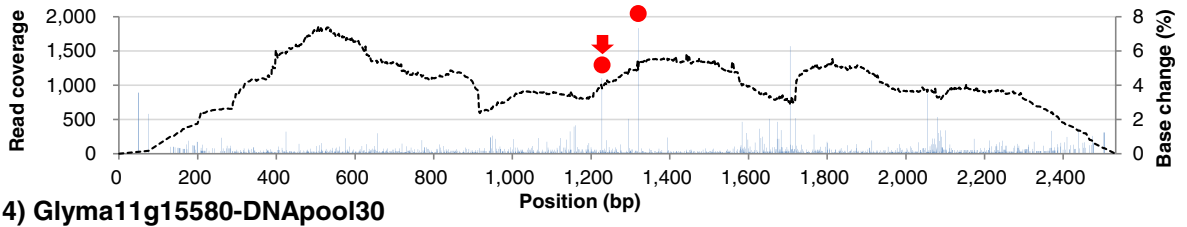

4) Glyma11g15580-DNApool30

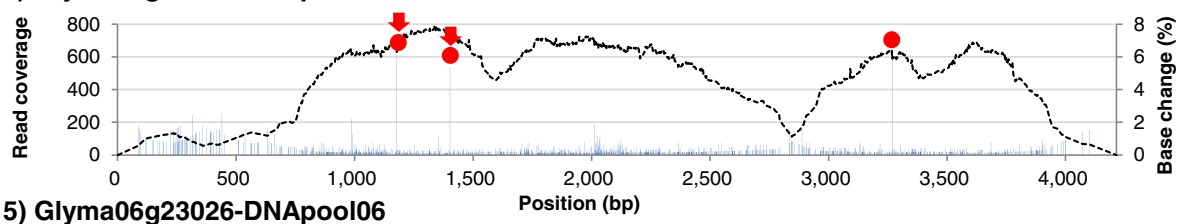

5) Glyma06g23026-DNApool06
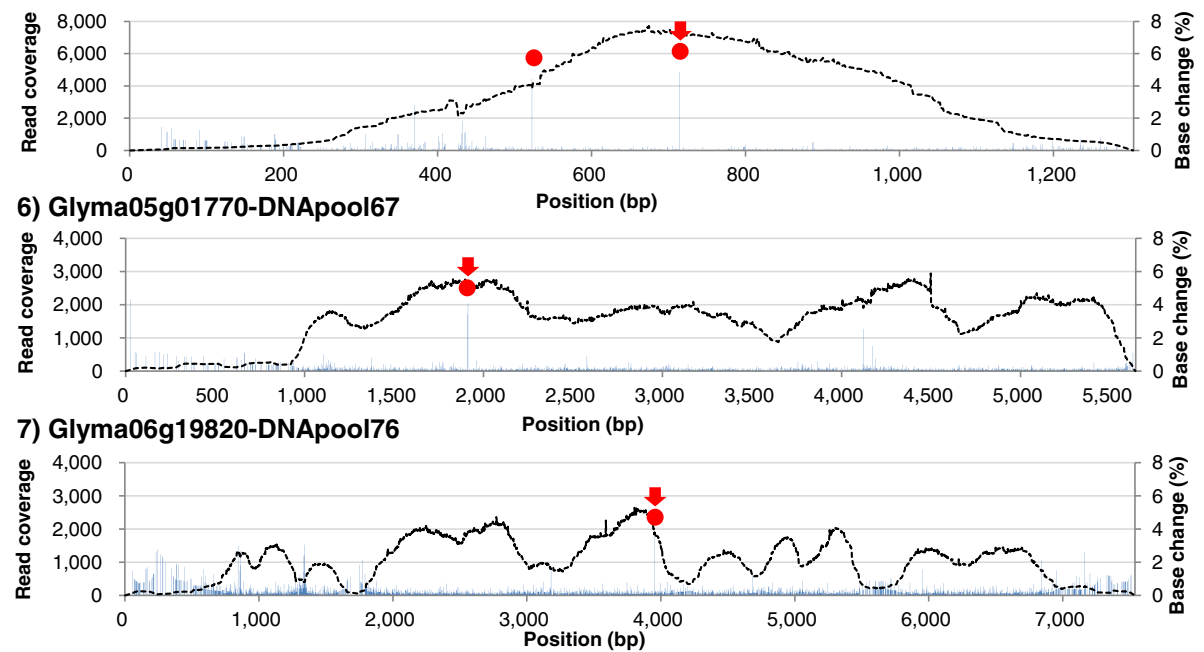

Fig. 6 Distribution of read coverage across seven amplicons and observed base changes in the DNA pool. Base change positions called as mutations are shown by red circles. Red arrows indicate confirmed by Sanger sequencing, respectively

Table 5 Comparison of mutation detection by high resolution melting analysis and indexed amplicon sequencing

\begin{tabular}{|c|c|c|c|c|c|c|c|}
\hline Gene locus & $\begin{array}{l}\text { Length } \\
\text { compared (bp) }\end{array}$ & $\begin{array}{l}\text { All base changes } \\
\text { obtained from } \\
\text { two methods }\end{array}$ & $\begin{array}{l}\text { Base changes } \\
\text { common to } \\
\text { both methods }\end{array}$ & $\begin{array}{l}\text { HRM } \\
\text { analysis only }\end{array}$ & $\begin{array}{l}\text { Index amplicon } \\
\text { sequencing only }\end{array}$ & $\begin{array}{l}\text { Percentage of } \\
\text { mutations detected } \\
\text { by HRM analysis (\%) }\end{array}$ & $\begin{array}{l}\text { Percentage of } \\
\text { mutations detected } \\
\text { by index amplicon } \\
\text { sequencing (\%) }\end{array}$ \\
\hline Glyma20g25000 & 1144 & 37 & 14 & 4 & 19 & 48.6 & 89.2 \\
\hline Glyma08g46520 & 487 & 22 & 13 & 1 & 8 & 63.6 & 95.5 \\
\hline Glyma06g23026 & 305 & 12 & 7 & 0 & 5 & 58.3 & 100.0 \\
\hline Glyma20g22160 & 1187 & 24 & 12 & 4 & 8 & 66.7 & 83.3 \\
\hline Glyma11g15580 & 380 & 12 & 7 & 2 & 3 & 75.0 & 83.3 \\
\hline Total & 3503 & 107 & 53 & 11 & 43 & 62.5 & 90.3 \\
\hline
\end{tabular}


A longer sequence range of indexed amplicon sequencing in comparison with HRM can be scanned all at once. Multiple gene copies impede mutation discovery in polyploid plants because it is difficult to design specific primers that can identify polymorphisms among copies of the same gene [17]. In contrast to HRM, in the proposed method of indexed amplicon sequencing it is not difficult to find specific primer pairs that can amplify a specific PCR amplicon because the choice of the target region is very flexible. Furthermore, the proposed method allows one to skip screening steps because it uses DNA pooling and a commercial dual indexing system, which enables simple and effective detection of plants with functional mutation and can be used as an alternative method for mutant screening. Since enlargement of present library toward 6000 lines are currently underway, severe adjustment of balance between number of target genes, the sequence range, number of indices and pooling individuals will be required to screen more mutants in the near future. Further advances in detection sensitivity which allow the detection of single molecules by third-generation sequencing is already described [33], but this technology still developing. The development of more cost-effective and higher-throughput whole-genome sequencing technologies would provide accurate data about mutations in all mutants in our upcoming library.

\section{Conclusions}

A soybean mutant library with a high mutation density was developed and various mutant phenotypes were observed at a high percentage in comparison with other previous soybean mutant libraries. A high mutation density (1 mutation per $74 \mathrm{~kb}$ ) was achieved by repeating the EMS treatment. Since multiple mutations probably mask the mutant phenotype of interest, confirmation of a functional mutation by the progeny analysis of test-cross with a wild-type plant is required. The mutation density of our library is sufficiently high to obtain a plant in which a gene is nonsense mutated. Thus, our mutant library and the indexed amplicon sequencing will be useful for functional studies of soybean genes and have a potential to yield useful mutant alleles for soybean breeding.

\section{Methods}

Plant materials, mutagenesis, and growth conditions

Mutagenesis was performed according to Anai [20]. The overall scheme of mutagenesis, plant propagation, and mutant library generation is shown in Fig. 1. Approximately 10,000 seeds of Japanese soybean (Glycine $\max$ L. Merr. cv. Enrei) were soaked for $8 \mathrm{~h}$ in a 0.35 \% EMS (Wako Pure Chemical Industries, Osaka, Japan) solution and then washed with running tapped water for overnight. Seeds were kept at $4{ }^{\circ} \mathrm{C}$ for 2 days prior to planting. M1 seedlings were grown in a vinyl house for 2 weeks and then transplanted to a field on the Hitachiomiya Campus of the National Institute of Agrobiological Sciences (NIAS) in Hitachiomiya, Ibaraki, Japan. The M1 plants (2000 individuals) were grown with an inter-row spacing of $70 \mathrm{~cm}$ and hill spacing of $10 \mathrm{~cm}$. Four M2 seeds were collected from each M1 plant, resulting in a total of 8000 seeds, which were mutagenized again with $0.35 \%$ EMS as above. These seeds were called M1' (Fig. 1), and M1' plants were grown as above. M2' seeds were harvested from individual M1' plants. The M2' plants were grown as above except that the inter-row spacing was $80 \mathrm{~cm}$ and hill spacing was $30 \mathrm{~cm}$ and M3' seeds were harvested at a field on the NIAS in Tsukuba, Ibaraki, Japan.

\section{Mutant evaluation}

During the growing season, M2' plants were examined for particular phenotypic changes that would distinguish them from wild-type 'Enrei'. The number of days from sowing to first flowering (R1) and full maturity (R8) [64] was recorded if these dates were at least one week earlier than those of wild-type. Protein, oil, sugar, and moisture contents in more than $10 \mathrm{~g}$ of the intact seeds were measured by near-infrared spectroscopy with a Foss Infratec 1241 Grain Analyzer using the calibration model SO138111 Soybeans STM (FOSS North America, Eden Prairie, MN, USA). Seeds from 242 M2' plants, M3' progenies and wild-type plants were examined (maximum four M3' progenies per M2' plant). Transmission spectra were recorded at a wavelength range of 570-1100 $\mathrm{nm}$. All values were recorded as means of three measurements per plant.

\section{DNA extraction}

Total genomic DNA of M2' plants was extracted from young fresh leaves $(0.3 \mathrm{~g})$ by using guanidine hydrochloride (Sigma-Aldrich, St. Louis, MO, USA) and proteinase K (QIAGEN, Valencia, CA, USA) according to Khosla et al. [65] with modifications. DNA concentration was measured with a Quant-i $\mathrm{T}^{\mathrm{TM}}$ PicoGreen dsDNA assay kit (Invitrogen, Carlsbad, CA, USA) according to the manufacturer's manual on a VIIA ${ }^{\mathrm{rm}} 7$ Real-Time PCR System (Life Technologies, Carlsbad, CA, USA) and adjusted to approximately $35 \mathrm{ng} / \mu \mathrm{l}$. Two multiplex PCR reactions that amplified 14 soybean SSR markers (Additional file 2: Table S1) were used to exclude contamination due to outcrossing with other materials according to the method of Kongjaimun et al. [66] with minor modifications. DNA samples were then pooled (four samples per well of a 384-well plate) and the DNA pool was used as a template DNA for screening. 
Detection of mutations by whole-genome re-sequencing Whole-genome re-sequencing was performed on a $\mathrm{HiSeq}^{\mathrm{Tm}}$ 2000 platform according to the manufacturer's instructions (Illumina) at Beijing Genomics Institute (Beijing, China). Briefly, a 100-bp paired-end library with an insert size of 500 bp was constructed by using genomic DNA from 12 M2' plants following the TruSeq ${ }^{\mathrm{TM}}$ protocol (Illumina). Read mapping and variant detection were performed with CLC Genomics Workbench 6.5.2 (CLC Bio, Aarhus, Denmark). To reduce sequencing errors, stringent filtering was applied to the raw reads with the following parameters: adaptor trim, ambiguous limit two, quality limit 0.01 , and removal of three 5'- and 3'-terminal nucleotides, discard read pairs with a minimum number of nucleotides less than $50 \mathrm{bp}$. The cleaned paired-end reads were mapped onto the soybean reference genome sequence (cultivar Williams 82, version Gmax_189; [3]) obtained from Phytozome FTP site [67] with the following parameters: no global alignment, auto-detect paired distances, mismatch cost two, deletion cost three, insertion cost three, length fraction 0.9 , and similarity fraction 0.96 . The complete genome sequences of soybean chloroplast (NC_007942) and mitochondrion (NC_020455) from the NCBI database [68] were also included as reference organelle genomes. SNV were identified in the aligned reads with probabilistic variant detection modules with the following parameters: ignore non-specific matches and broken read pairs, minimum read coverage five, variant probability $40 \%$, and presence in both forward and reverse reads required. Insertions and deletions were excluded from analysis. To remove variations of paralogous reads and variations between Williams 82 and Enrei, another SNV set was collected for each plant by using the same modules with the following relaxed parameters: non-specific matches and broken read pairs included, minimum read coverage two, variant probability $10 \%$, and maximum expected variants four. By comparing the sets from 12 M2' plants to each other, a variant filter to distinguish unrelated variation from mutations was prepared based on a common frequency threshold of $20 \%$. Using this variant filter, a set of high-confidence single nucleotide changes that occurred because of EMS treatment was created for each plant. Position of mutations overlapping with known gene annotations and those resulting in amino acid changes were searched by using amino acid changes annotation module against the annotated version of Gmax_189 obtained from Phytozome FTP site [67].

\section{Primer design}

Primers were designed on the basis of the reference soybean genome sequence by using Primer3 [69] with default parameters. To ensure specificity, primer sequences were searched against Gmax_189 to examine the number of potential binding sites, amplicon size and location by using
Genome Tester [70] with default parameters until a single amplicon was obtained. For HRM analysis, 16 primers (Additional file 2: Table S2) were designed to amplify fragments shorter than 500 bp for Glyma20g25000, Glyma08g46520, Glyma06g23026, Glyma11g15580, and Glyma20g22160. For amplicon sequencing, seven primer pairs (Additional file 2: Table S3) were designed to amplify long fragments (1.3-7.5 kb) of Glyma05g01770 and Glyma06g19820 in addition to the above five genes.

\section{HRM analysis}

Mutations were detected with a VIIA ${ }^{\mathrm{Tm}} 7$ Real-Time PCR System (Life Technologies). Reaction mixtures consisted of either $5 \mu \mathrm{l}$ of MeltDoctor ${ }^{\mathrm{TM}}$ HRM master mix (Life Technologies), $2.5 \mu \mathrm{l}$ of $10 \mu \mathrm{M}$ forward and reverse primers, and $0.2 \mu \mathrm{l}$ of the template DNA in a total volume of $10 \mu \mathrm{l}$, or $5 \mu \mathrm{l}$ of $2 \times$ GoTaq $^{\bullet}$ Colorless Master Mix (Promega, Madison, WI, USA), $2.5 \mu \mathrm{l}$ of $10 \mu \mathrm{M}$ forward and reverse primers, $0.003 \mu \mathrm{l}$ of $5 \mathrm{mM} \mathrm{SYTO}^{\circ} 9$ green fluorescent nucleic acid stain (Life Technologies), and $0.2 \mu \mathrm{l}$ of the template DNA in a total volume of $10 \mu \mathrm{l}$. For MeltDoctor ${ }^{\mathrm{Tm}}$ HRM master mix, the PCR thermal cycler was programmed as follows: 1 cycle of initial denaturation at $95{ }^{\circ} \mathrm{C}$ for $10 \mathrm{~min}$; 40 cycles of denaturation for $15 \mathrm{~s}$ at $95{ }^{\circ} \mathrm{C}$, annealing for $30 \mathrm{~s}$ at $53{ }^{\circ} \mathrm{C}$, and extension for $1.5 \mathrm{~min}$ at $60{ }^{\circ} \mathrm{C}$. For $\mathrm{GoTaq}^{\circ}$ Colorless Master Mix, the initial denaturation time was 2 min and denaturation time was $30 \mathrm{~s}$. The thermal shift for HRM consisted of five steps: denaturation for $10 \mathrm{~s}$ at $95{ }^{\circ} \mathrm{C}$; annealing for $1 \mathrm{~min}$ at $60{ }^{\circ} \mathrm{C}$, then raising the temperature at a rate of $0.015{ }^{\circ} \mathrm{C} / \mathrm{s}$ for denaturation and fluorescence data acquisition; $15 \mathrm{~s}$ at $95{ }^{\circ} \mathrm{C}$, and $15 \mathrm{~s}$ at $60{ }^{\circ} \mathrm{C}$. Melting profiles of PCR amplicons were obtained with the ViiA7 real-time PCR system software, v. 1.2.2 (Life Technologies). To optimize the DNA pooling conditions, HRM analysis of the Ln_ex1 region of Glyma20g25000 (380 bp, Additional file 2: Table S2) was performed using mixtures of the wildtype gene and mutated gene (Asp9His) at various ratios: $1: 1,1: 2,1: 3,1: 4,1: 5,1: 6,1: 7,1: 8,1: 9,1: 10,1: 11,1: 12,1: 13$, $1: 14,1: 15$, and $1: 16$. The $1: 1$ to $1: 8$ mixtures allowed us to clearly distinguish between the mutant profile and the wildtype profile based on the difference plot generated by the software; therefore, the most suitable pooling condition to identify heterozygous mutants was determined to be four samples (eight copies in haploids). For mutation screening, 384 DNA pools (four samples per pool) from 1536 M2' plants were used. The initial screening for DNA pools containing mutations was repeated at least three times. Then, four DNA samples from the pool in which a mutation was detected were sequenced separately to determine the mutated sequence. The PCR products for sequencing were amplified by using $\mathrm{GoTaq}^{\circ}$ Colorless Master Mix as above and cleaned with ExoSAP-IT (USB Corporation, Cleveland, $\mathrm{OH}, \mathrm{USA})$. Sequencing was performed with an ABI Prism 
BigDye terminator v 3.1 cycle sequencing kit (Applied Biosystems) and 5 pmol of the primer on an ABI-3730xl automated DNA analyzer (Applied Biosystems) according to the manufacturer's manual. The sequence chromatograms were aligned to the reference sequence with Sequencher 5.2 (Gene Codes Corporation, Ann Arbor, MI, USA) and the difference between wild-type Enrei and the mutant was identified.

\section{Indexed amplicon sequencing}

Long-range PCR (1.3-7.5 kb) was conducted to amplify seven genes: Glyma05g01770, Glyma06g19820, Glyma06g23026, Glyma08g46520, Glyma11g15580, Glyma20g22160, and Glyma20g25000 (see Additional file 2: Table S3 and Additional file 1: Figure S2 for primer pairs). PCR reaction mixtures $(10 \mu \mathrm{l})$ contained $0.2 \mu \mathrm{l}$ of template DNA from each of the 384 DNA pools described above, $2 \mu \mathrm{l}$ of $5 \times$ PrimeSTAR GXL Buffer (Takara Bio, Shiga, Japan), $1.0 \mu \mathrm{l}$ of PrimeSTAR GXL DNA Polymerase $(1.25 \mathrm{U} / \mu \mathrm{l}), 0.8 \mu \mathrm{l}$ of $2.5 \mathrm{mM}$ dNTPs, and $0.1 \mu \mathrm{l}$ of $20 \mu \mathrm{M}$ forward and reverse primers. PCR reactions were performed on a GeneAmp PCR System 9700 (Applied Biosystems) with the following programs: for Glyma05g01770 and Glyma06g19820, initial denaturation for $5 \mathrm{~s}$ at $98^{\circ} \mathrm{C} ; 30$ cycles of denaturation for $10 \mathrm{~s}$ at $98^{\circ} \mathrm{C}$, annealing for $15 \mathrm{~s}$ at $68^{\circ} \mathrm{C}$, and extension for $7 \mathrm{~min}$ $35 \mathrm{~s}$ at $68^{\circ} \mathrm{C}$; and final extension for $30 \mathrm{~s}$ at $68^{\circ} \mathrm{C}$; for Glyma08g46520, Glyma06g23026, and Glyma20g25000 the extension time was decreased to $2 \mathrm{~min} 30 \mathrm{~s}$, and the annealing temperature for these three genes and for Glyma20g22160 and Glyma11g15580 was decreased to $60^{\circ} \mathrm{C}$. Single banding pattern of PCR amplicons from several rows of a 384 well plate were visually confirmed by $1 \%$ agarose gel electrophoresis and quantified with a Quant$\mathrm{iT}^{\mathrm{mx}}$ PicoGreen dsDNA assay kit (Invitrogen). According to the amplicon sizes and approximate concentrations, PCR amplicons of seven genes were combined in equimolar amounts keeping a 384-well format. Four of the combined 384 samples were mixed as described in Fig. 2 to prepare 96 PCR amplicon pools. The pools were purified by ethanol precipitation and were diluted to $0.2 \mathrm{ng} / \mu \mathrm{l}$. A DNA library for sequencing was prepared by using the transposome-based Nextera ${ }^{\mathrm{Tm}}$ XT DNA Sample Preparation Kit and Nextera ${ }^{\mathrm{Tm}}$ XT Index Kit (Illumina). The 96 samples were indexed by using 12 different i7 and eight different i5 adaptors, and mixed. Paired-end sequencing (250 bp) was performed on a MiSeq qu $^{\text {TI }}$ platform using a MiSeq $^{\text {tm }}$ v2 500-cycle kit (Illumina) with default parameters. Fluorescent images were analyzed with the MiSeq ${ }^{\text {ma }}$ Control software, and FASTQ-formatted sequence data after demultiplexing was created by using $\mathrm{MiSeq}^{\mathrm{Tw}} \mathrm{Re}-$ porter software. Read mapping and variant detection were undertaken with the CLC Genomics Workbench software using a workflow tool and batch processing of 96 samples.
The parameters for sequence trimming and read mapping were the same as for the detection of mutations by wholegenome re-sequencing. Cleaned paired-end reads were mapped onto the target reference sequences. Sequences at polymorphic sites between the donor of the reference sequence and the donor of the mutant library (between Williams 82 and Enrei) were replaced with the sequence of the mutant library donor Enrei in advance to the read mapping. SNVs were identified with quality variant detection modules using the following parameters: ignore nonspecific matches and broken read pairs, neighborhood radius five, maximum gap and mismatch count two, minimum neighborhood quality 15 , minimum central quality 20 , maximum expected alleles four, minimum read coverage 96 , minimum variant frequency $2.1 \%$, and presence in both forward and reverse reads required. The combination of the minimum read coverage 96 and variant frequency $2.1 \%$ parameters corresponded to two reads with a base change among 96 reads per pool. Insertions and deletions were excluded from a analysis. Finally, the mutations predicted to change amino acids were analyzed by using the annotated version of Gmax_189.

\section{Availability of supporting data}

The raw sequence reads for all mutant lines are available under DDBJ (DNA Data Bank of Japan) Sequence Read Archive accession number 'DRA004035-DRA004046' (http://trace.ddbj.nig.ac.jp/DRASearch).

\section{Additional files}

Additional file 1: Figure S1. Regions of Glyma20g25000 scanned by using HRM analysis and indexed amplicon sequencing. Yellow, coding regions; green, transcripts; red, regions scanned by using HRM analysis; purple, the region indexed by using amplicon sequencing analysis. The labels indicate either the gene name (Glyma) or target regions in Additional file 2: Table S2 and Table S3. Figure S2. Structures of seven genes analyzed by using indexed amplicon sequencing. Yellow, coding regions; green, transcripts; red, primer binding sites. The labels indicate either gene names (Glyma) or primer names. Figure S3. Variation of read coverage by sample well location. (PPTX $272 \mathrm{~kb}$ )

Additional file 2: Table S1. Soybean simple sequence repeat markers. Table S2. Primer pairs for high resolution melting analysis. Table S3. Primer pairs for amplicon sequencing. (DOCX 33 kb)

\section{Abbreviations}

EMS: Ethyl methanesulfonate; NGS: Next generation sequencing; HRM: High resolution melting; SSR: Simple sequence repeat; SNV: Single nucleotide variants; NIAS: National Institute of Agrobiological Sciences;

TILLING: Targeting-induced local lesions in genomes.

\section{Competing interests}

The authors declare no competing interests.

\section{Author's contributions}

AK conceived and designed the experiments. MT, AK, NY, and MI evaluated mutant phenotypes. TA determined EMS treatment conditions. SW and MN grew initial mutant progenies. HRM analysis was performed by TS, KT, and KM. Amplicon sequencing was performed by TS, SM, HS, HK, and YK. TS and KM conducted Sanger sequencing. AK carried out bioinformatics analysis of 
NGS data. MT wrote the paper. AK and MI critically revised of the manuscript. All authors read and approved the final manuscript.

\section{Author's information}

Mai Tsuda is the first author.

Akito Kaga is the corresponding author.

\section{Acknowledgements}

The authors appreciate technical support in handling field materials from the following staff of the National Institute of Agrobiological Sciences (NIAS): Yagihashi M, Nemoto H, Karino N, Sugimoto K, Taguchi T, Tsubokura Y, Tobita M, Hiyama K, and Shimane K. We thank Dr. Jun-ichi Yonemaru (NIAS) for helping to draw chromosome ideograms. This work was supported by a grant from the Ministry of Agriculture, Forestry, and Fisheries of Japan (IVG1005) and partially by NIAS Strategic Research Fund.

\section{Author details}

${ }^{1}$ Agronomics Research Center, National Institute of Agrobiological Sciences, 2-1-2 Kannondai, Tsukuba, Ibaraki 305-8602, Japan. ²Present address: Gene Research Center, Faculty of Life and Environmental Sciences, University of Tsukuba, 1-1-1, Ten-nodai, Tsukuba, Ibaraki 305-8574, Japan. ${ }^{3}$ Faculty of Agriculture, Saga University, 1 Honjo-machi, Saga 840-8502, Japan. ${ }^{4}$ Present Address: Soil Science and Plant Nutrition Division, National Agriculture and Food Research Organization Agricultural Research Center, 3-1-1, Kannondai, Tsukuba, Ibaraki 305-8666, Japan. ${ }^{5}$ Present Address: Faculty of Agriculture, Niigata University, 8050, Ikarashi 2-no-cho, Nishi-ku, Niigata 950-2181, Japan. ${ }^{6}$ Nagano Vegetable and Ornamental Crops Experiment Station, 1066-1, Soga, Shiojiri, Nagano 399-6461, Japan.

Received: 10 April 2015 Accepted: 13 October 2015 Published online: 26 November 2015

\section{References}

1. Singh RJ, Hymowitz T. Soybean genetic resources and crop improvement. Genome. 1999;42:605-16. doi:10.1139/gen-42-4-605.

2. Phytozome v9.1: Glycine max v1.1. http://genome.jgi.doe.gov/pages/ dynamicOrganismDownload.jsf?organism=PhytozomeV9. Accessed 28 October 2015.

3. Schmutz J, Cannon SB, Schlueter J, Ma J, Mitros T, Nelson W, et al. Genome sequence of the paleopolyploid soybean. Nature. 2010;463:178-83. doi:10.1038/nature08670.

4. Chen L, Huang L, Min D, Phillips A, Wang S, Madgwick PJ, et al. Development and characterization of a new TILLING population of common bread wheat (Triticum aestivum L.). PLoS One. 2012;7, e41570. doi:10.1371/journal.pone.0041570.

5. Stadler $L$. Chromosome number and the mutation rate in Avena and Triticum. Proc Natl Acad Sci USA. 1929;15:876-81.

6. Roulin A, Auer PL, Libault M, Schlueter J, Farmer A, May G, et al. The fate of duplicated genes in a polyploid plant genome. Plant J. 2013;73:143-53. doi:10.1111/tpj.12026.

7. Liu B, Kanazawa A, Matsumura H, Takahashi R, Harada K, Abe J. Genetic redundancy in soybean photoresponses associated with duplication of the phytochrome A gene. Genetics. 2008;180:995-1007. doi:10.1534/ genetics.108.092742.

8. Ohno S. Evolution by gene duplication. New York: Splinger-Verlag; 1970.

9. Mba C, Shu QY. Gamma irradiation. In: Shu QY, Forster BP, Nakagawa H, editors. Plant mutation breeding and biothechnology. Italy: CAB International and FAO; 2012. p. 91-8.

10. Morita R, Kusaba M, lida S, Yamaguchi H, Nishio T, Nishimura M. Molecular characterization of mutations induced by gamma irradiation in rice. Genes Genet Syst. 2009;84:361-70. http://dx.doi.org/10.1266/ggs.84.361.

11. McCallum CM, Comai L, Greene EA, Henikoff S. Targeting Induced Local Lesions IN Genomes (TILLNG) for plant functional genomics. Plant Physiol. 2000;123:439-42. http://dx.doi.org/10.1104/pp.123.2.439.

12. Till BJ, Reynolds SH, Weil C, Springer N, Burtner C, Young K, et al. Discovery of induced point mutations in maize genes by TILLING. BMC Plant Biol. 2004:4:12. doi:10.1186/1471-2229-4-12.

13. Till BJ, Cooper J, Tai TH, Colowit P, Greene EA, Henikoff S, et al. Discovery of chemically induced mutations in rice by TILLING. BMC Plant Biol. 2007;7:19. doi:10.1186/1471-2229-7-19.
14. Blomstedt GK, Gleadow RM, O'Donnell N, Nur P, Jensen K, Lursen T, et al. A combined biochemical screen and TILLING approach identifies mutations in Sorghum bicolor L. Moench resulting in acyanogenic forage production. Plant Biotech J. 2012;10:54-66. doi:10.1111/j.1467-7652.2011.00646.x.

15. Cooper JL, Till BJ, Laport RG, Darlow MC, Kleffner JM, Jamai A, et al. TILLING to detect induced mutations in soybean. BMC Plant Biol. 2008;8:9. doi:10.1186/1471-2229-8-9.

16. Okabe Y, Asamizu E, Saito T, Matsukura C, Ariizumi T, Brès $C$, et al. Tomato TILLING technology: Development of a reverse genetics tool for the efficient isolation of mutants from micro-tom mutant libraries. Plant Cell Physiol. 2011;52:1994-2005. doi:10.1093/pcp/pcr134.

17. Gilchrist EJ, Sidebottom CHD, Koh CS, Maclnnes T, Sharpe AG, Haughn GW A mutant Brassica napus (Canola) population for the identification of new genetic diversity via TILLING and next generation sequencing. PLoS One. 2013;8:e84303. doi:10.1371/journal.pone.0084303.

18. Leitão JM. Chemical mutagenesis. In: Shu QY, Forster BP, Nakagawa H, editors. Plant mutation breeding and biotechnology. Italy: CAB International and FAO; 2012. p. 135-58.

19. Khan MH, Tyagi SD. A review on induced mutagenesis in soybean. J Cereals Oilseeds. 2013;4:19-25. doi:10.5897/JCO10.004.

20. Anai T. Potential of a mutant-based reverse genetic approach for functional genomics and molecular breeding in soybean. Breed Sci. 2012;61:462-7. doi:10.1270/jsbbs.61.462.

21. Colbert T, Till BJ, Tompa R, Reynolds S, Steine MN, Yeung AT, et al. Highthroughput screening for induced point mutations. Plant Physiol. 2001;126:480-4. http://www.ncbi.nlm.nih.gov/pmc/articles/PMC1540114/.

22. Comai L, Henikoff S. TILLING: practical single-nucleotide mutation discovery. Plant J. 2006:45:684-94. doi:10.1111/j.1365-313X.2006.02670.x.

23. Wittwer CT, Reed GH, Gundry CN, Vandersteen JG, Rryor RJ. High-resolution genotyping by amplicon melting analysis using LCGreen. Clin Chem. 2003;49:853-60. doi:10.1373/49.6.853.

24. Wittwer CT. High-resolution DNA, melting analysis: Advancements and limitations. Hum Mutat. 2009;30:857-9. doi:10.1002/humu.20951.

25. Gady ALF, Hermans FWK, Wal MHBJVD, Loo ENV, Visser RGF, Bachem CWB. Implementation of two high through-put techniques in a novel application: detecting point mutations in large EMS mutated plant populations. Plant methods. 2009;5:13-26. doi:10.1186/1746-4811-5-13.

26. Dong C, Vincent K, Sharp P. Simultaneous mutation detection of three homoeologous genes in wheat by High resolution melting analysis and Mutation Surveyor ${ }^{\oplus}$. BMC Plant Biol. 2009;9:143. doi:10.1186/1471-2229-9-143.

27. Venter JC, Adams MD, Myers EW, Li PW, Mural RJ, Sutton GG, et al. The sequence of the human genome. Science. 2001;291:1304-51. doi:10.1126/ science.1058040.

28. Sanger F, Nicklen S, Coulson AR. DNA sequencing with chain-terminating inhibitors. Proc Nati Acad Sci USA. 1977;74:5463-7.

29. Margulies M, Egholm M, Altman WE, Attiya S, Bader JS, Bemben LA, et al. Genome sequencing in microfabricated high-density picolitre reactors. Nature. 2005;437:376-80. doi:10.1038/nature03959.

30. Bentley DR, Balasubramanian S, Swerdlow HP, Smith GP, Milton J, Brown $C G$, et al. Accurate whole human genome sequencing using reversible terminator chemistry. Nature. 2008;456:53-9. doi:10.1038/nature07517.

31. Valouev A, Ichikawa J, Tonthat T, Stuart J, Ranade S, Peckham H, et al. A high-resolution, nucleosome position map of $C$. elegans reveals a lack of universal sequence-dictated positioning. Genome Res. 2008;18:1051-63. doi:10.1101/gr.076463.108.

32. Rothberg JM, Hinz W, Rearick TM, Schultz J, Mileski W, Davey M, et al. An integrated semiconductor device enabling non-optical genome sequencing. Nature. 2011;475:348-52. doi:10.1038/nature10242.

33. Dijk ELV, Auger $H$, Jaszczyszyn $Y$, Thermes $C$. Ten years of next-generation sequencing technology. Trends Genet. 2014;30:418-26. doi:10.1016/ j.tig.2014.07.001.

34. Tsai H, Howell T, Nitcher R, Missirian V, Watson B, Ngo KJ, et al. Discovery of rare mutations in populations: TILLING by sequencing. Plant Physiol. 2011;156:1257-68. doi:10.1104/pp. 110.169748.

35. Zhu Q, Smith SM, Ayele M, Yang L, Jogi A, Chaluvadi SR, et al. Highthroughput discovery of mutations in Tef semi-dwarfing genes by nextgeneration sequencing analysis. Genetics. 2012;192:819-29. doi:10.1534/ genetics.112.144436.

36. Wells R, Trick M, Fraser F, Soumpourou E, Clissold L, Morgan C, et al. Sequencing-based variant detection in the polyploid crop oilseed rape. BMC Plant Biol. 2013;13:111. doi:10.1186/1471-2229-13-111. 
37. Schlötterer C, Tobler R, Kofler R, Nolte V. Sequencing pools of individuals mining genome-wide polymorphism data without big funding. Nat Rev Genet. 2014;15:749-63. doi:10.1038/nrg3803.

38. Adey A, Morrison HG, Asan, Xun X, Kitzman JO, Turner EH, et al. Rapid, low-input, low-bias construction of shotgun fragment libraries by high-density in vitro transposition. Genome Biol. 2010;11:R119. doi:10.1186/gb-2010-11-12-r119.

39. Lamble S, Batty E, Attar M, Buck D, Bowden R, Lunter G, et al. Improved workflows for high throughput library preparation using the transposome-based nextera system. BMC Biotechnol. 2013;13:104. doi:10.1186/1472-6750-13-104.

40. Karthika R, Lakshmi S. Effect of Gamma rays and EMS on two varieties of soybean. Asian J Plant Sci. 2006;5:721-4. doi:10.3923/ajps.2006.721.724.

41. Akao S, Kouchi H. A supernodulating mutant isolated from soybean cultivar Enrei. Soil Sci Plant Nutr. 1992;38:183-7. doi:10.1080/00380768.1992.10416966.

42. Khan MH, Tyagi SD. Cytological effects of different mutagens in soybean [Glycine max (L.) Merrill]. Front. Agric China. 2009;4:397-401. doi:10.1007/ s11703-009-0065-3.

43. Porch TG, Blair MW, Lariguet P, Galeano C, Pankhurst CE, Broughton WJ. Generation of a mutant population for TILLING common bean genotype BAT 93. J Amer Soc Hort Sci. 2009;134:348-55.

44. Minola S, Petrozza A, D'Onofrio O, Piron F, Mosca G, Sozio G, et al. A new mutant genetic resource for tomato crop improvement by TILLING technology. BMC Res Notes. 2010;3:69. doi:10.1186/1756-0500-3-69.

45. Toda K, Ono T, Kitamura K, Nakamura Y. Seed protein content and consistency of Tofu prepared with different magnesium chloride concentrations in six Japanese soybean varieties. Breed Sci. 2003;53:217-23. doi:10.1270/jsbbs.53.217.

46. Wang HL, Swain EW, Kwolek WF. Effect of soybean varieties on the yield and quality of Tofu. Cereal Chem. 1983;60:245-8.

47. Watanabe I, Nagasawa T. Appearance and chemical composition of soybean seeds in germplasm collection of Japan: I. A Frequency distribution of grain size, seed coat colour, hilum colour and content of chemical component, with special reference to collection site. Jpn J Crop Sci. 1990;59:649-60 (in Japanese)

48. Hwang EY, Song Q, Jia G, Specht JE, Hyten DL, Costa J, et al. A genomewide association study of seed protein and oil content in soybean. BMC Genomics. 2014;15:1. doi:10.1186/1471-2164-15-1.

49. Arefrad M, Nematzadeh G, Jelodar NB, Kazemitabar SK. Improvement of qualitative and quantitative traits in soybean [Glycine Max (L.) Merrill] through gamma irradiation. JPMB. 2012;1:10-5.

50. Cober ER, Voldeng HD. Developing high-protein, high-yield soybean populations and lines. Crop Sci. 2000;40:39-42. doi:10.2135/cropsci2000.40139x.

51. Mujoo R, Trinh DT, Ng PKW. Characterization of storage proteins in different soybean varieties and their relationship to tofu yield and texture. Food chem. 2003;82:265-73. doi:10.1016/S0308-8146(02)00547-2.

52. Riblett AL, Herald TJ, Schmidt KA, Tilley KA. Characterization of betaconglycinin and glycinin soy protein fractions from four selected soybean genotypes. J Agric Food Chem. 2001;49:4983-9. doi:10.1021/jf0105081.

53. Petruccelli S, Anon MC. Soy protein isolate components and their interactions. J Agric Food Chem. 1995;43:1762-7. doi:10.1021/jf00055a004.

54. Teraishi M, Okumoto Y, Yoshikawa T, Endo R, Tanisaka T. Identification of genes controlling the contents of seed storage proteins in soybean -Fine mapping of the Quantitative trait locus QPro7-. Soy protein research, Japan. 2010;13:51-4.

55. SoyBase, the USDA-ARS Genetics and Genomics Database. 2015. Grant D, Nelson RT, Cannon SC. http://soybase.org. Accessed 28 October 2015.

56. Abe A, Kosugi S, Yoshida K, Natsume S, Takagi H, Kanzaki H, et al. Genome sequencing reveals agronomically important loci in rice using MutMap. Nature Biotechnol. 2012;30:174-3. doi:10.1038/nbt.2095.

57. Shirasawa K, Hirakawa H, Nunome T, Tabata S, Isobe S. Genome-wide survey of artificial mutations induced by ethyl methanesulfonate and gamma rays in tomato. Plant Biotech J. 2015:1-10. doi: 10.1111/pbi.12348.

58. Miller JN, Pearce DA. Nonsense-mediated decay in genetic disease: friend or foe? 2014;762:52-64. doi:10.1016/j.mrrev.2014.05.001.

59. Jeong N, Suh SJ, Kim MH, Lee S, Moon JK, Kim HS, et al. Ln is a key regulator of leaflet shape and number of seeds per pod in soybean. Plant Cell. 2012;24:4807-18. doi:10.1105/tpc.112.104968.

60. Shibuya M, Hoshino M, Katsube Y, Hayashi H, Kushiro T, Ebizuka Y. Identification of b-amyrin and sophoradiol 24-hydroxylase by expressed sequence tag mining and functional expression assay. FEBS J. 2006;273:948-59. doi:10.1111/j.1742-4658.2006.05120.x.
61. Xia Z, Watanabe S, Yamada T, Tsubokura Y, Nakashima H, Zhai H, et al. Positional cloning and characterization reveal the molecular basis for soybean maturity locus E1 that regulates photoperiodic flowering. Proc Natl Acad Sci USA. 2012;109:E2155-64. doi:10.1073/pnas.1117982109.

62. Xia Z, Zhai H, Liu B, Kong F, Yuan X, Wu H, et al. Molecular identification of genes controlling flowering time, maturity, and photoperiod response in soybean. Plant Syst Evol. 2012;298:1217-27. doi:10.1007/s00606-012-0628-2.

63. Juwattanasomran R, Somta P, Chankaew S, Shimizu T, Wongpornchai S, Kaga A, et al. A SNP in GmBADH2 gene associates with fragrance in vegetable soybean variety "Kaori" and SNAP marker development for the fragrance. Theor Appl Genet. 2011;122:533-41. doi:10.1007/s00122-010-1467-6.

64. Fehr WR, Caviness CE, Burmood DT, Pennngton JS. Stage of development descriptions for Soybeans, Glycine Max (L.) Merrill. Crop Sci. 1971;11:929-31. doi:10.2135/cropsci1971.0011183X001100060051x.

65. Khosla S, Augustus M, Brahmachari V. Sex-specific organisation of middle repetitive DNA sequences in the mealybug Planococcus lilacinus. Nucleic Acids Res. 1999;27:3745-51. doi:10.1093/nar/27.18.3745.

66. Kongjaimun A, Kaga A, Tomooka N, Somta P, Shimizu T, Shu Y, et al. An SSR-based linkage map of yardlong bean (Vigna unguiculata (L.) Walp. subsp. unguiculata Sesquipedalis Group) and QTL analysis of pod length. Genome. 2012;55:81-92. doi:10.1139/G11-078.

67. Phytozome download site. http://genome.jgi.doe.gov/pages/ dynamicOrganismDownload.jsf?organism=PhytozomeV9; Accessed on 28 October 2015.

68. NCBI data base. http://www.ncbi.nlm.nih.gov/nuccore/. Accessed 28 October 2015.

69. Rozen S, Skaletsky HJ. Primer3 on the WWW for general users and for biologist programmers. In: Krawetz S, Misener S, editors. Bioinformatics methods and protocols: Methods in molecular biology. Totowa, NJ: Humana Press; 2000. p. 365-86.

70. Anderson R, Reppo E, Kaplinski L, Remm M. GENOMEMASKER package for designing unique genomic PCR primers. BMC Bioinfo. 2006;7:172. doi:10.1186/1471-2105-7-172.

\section{Submit your next manuscript to BioMed Central and take full advantage of:}

- Convenient online submission

- Thorough peer review

- No space constraints or color figure charges

- Immediate publication on acceptance

- Inclusion in PubMed, CAS, Scopus and Google Scholar

- Research which is freely available for redistribution 